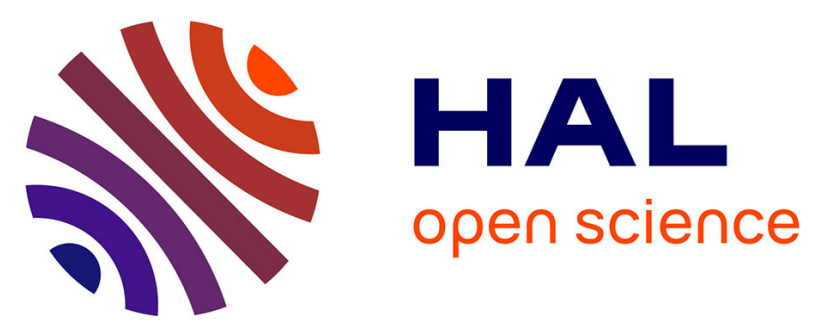

\title{
Lost in translation: egg transcriptome reveals molecular signature to predict developmental success and novel maternal-effect genes
}

\author{
Caroline T. Cheung, Thuy Thao Vi Nguyen, Aurélie Le Cam, Amélie \\ Patinote, Laurent Journot, Christelle Reynes, Julien Bobe
}

\section{To cite this version:}

Caroline T. Cheung, Thuy Thao Vi Nguyen, Aurélie Le Cam, Amélie Patinote, Laurent Journot, et al.. Lost in translation: egg transcriptome reveals molecular signature to predict developmental success and novel maternal-effect genes. 2018. hal-03169273

\section{HAL Id: hal-03169273 \\ https://hal.inrae.fr/hal-03169273}

Preprint submitted on 15 Mar 2021

HAL is a multi-disciplinary open access archive for the deposit and dissemination of scientific research documents, whether they are published or not. The documents may come from teaching and research institutions in France or abroad, or from public or private research centers.
L'archive ouverte pluridisciplinaire HAL, est destinée au dépôt et à la diffusion de documents scientifiques de niveau recherche, publiés ou non, émanant des établissements d'enseignement et de recherche français ou étrangers, des laboratoires publics ou privés. 


\section{Lost in translation: egg transcriptome reveals molecular signature to predict developmental success and novel maternal-effect genes}

Caroline T. Cheung ${ }^{1}$, Thaovi Nguyen ${ }^{1}$, Aurélie Le Cam ${ }^{1}$, Amélie Patinote ${ }^{1}$, Laurent Journot ${ }^{2,3}$, Christelle Reynes ${ }^{2}$, Julien Bobe ${ }^{1 *}$

${ }^{1}$ INRA LPGP UR1037, Campus de Beaulieu, 35042 Rennes, France.

2 Institut de Génomique Fonctionnelle, CNRS UMR5203, INSERM U1191, Université de Montpellier, Montpellier, France.

${ }^{3}$ Montpellier GenomiX, BioCampus Montpellier, CNRS UMS3426, INSERM US009, Université de Montpellier, Montpellier, France.

* Corresponding author : julien.bobe@inra.fr

Short title : Maternal egg transcriptome reflects developmental success

Word count: 7952

Number of figures: 8 


\section{Abstract}

Background: Good quality or developmentally competent eggs result in high survival of progeny. Previous research has shed light on factors that determine egg quality, however, large gaps remain. Initial development of the embryo relies on maternally-inherited molecules, such as transcripts, deposited in the egg, thus, they would likely reflect egg quality. We performed transcriptome analysis on zebrafish fertilized eggs of different quality from unrelated, wildtype couples to obtain a global portrait of the egg transcriptome to determine its association with developmental competence and to identify new candidate maternal-effect genes. Results: Fifteen of the most differentially expressed genes (DEGs) were validated by quantitative real-time PCR. Gene ontology analysis showed that enriched terms included ribosomes and translation. In addition, statistical modeling using partial least squares regression and genetics algorithm also demonstrated that gene signatures from the transcriptomic data can be used to predict reproductive success. Among the validated DEGs, otulina and slc29a1a were found to be increased in good quality eggs and to be predominantly localized in the ovaries. CRISPR/Cas9 knockout mutants of each gene revealed remarkable subfertility whereby the majority of their embryos were unfertilizable. The Wnt pathway appeared to be dysregulated in the otulina knockout-derived eggs. Conclusions: Our novel findings suggested that even in varying quality of eggs due to heterogeneous causes from unrelated wildtype couples, gene signatures exist in the egg transcriptome, which can be used to predict developmental competence. Further, transcriptomic profiling revealed two new potential maternal-effect genes that have essential roles in vertebrate reproduction.

Keywords: egg quality, transcriptome, microarray, zebrafish, prediction model 


\section{Background}

Good quality or developmentally competent fish eggs are defined as those that are successfully fertilized and develop normally as viable, non-malformed embryos that hatch[1]. However, the detailed mechanisms that are involved in egg quality and developmental competence are still poorly understood, and at present, no predictive markers of egg quality exist. Maternal-effect genes are those that produce factors that are involved in the earliest stages of embryonic development, including fertilization, parental genome union, and cell division. Since initial development of the embryo relies on these maternally-inherited molecules including coding and non-coding mRNAs and proteins that are deposited into the developing oocyte, thus, they would likely reflect egg quality[2,3]. Among these, the maternally-provided transcriptome of the egg is critical in kick-starting early embryogenesis because transcription from the zygotic genome does not start until the mid-blastula transition (MBT) which occurs approximately 3-4 hours post-fertilization (hpf) in zebrafish[4,5].

Previous research using both traditional mutational assays as well as more recent transcriptomic analyses have revealed several maternal factors that can influence egg quality. The nucleoplasmin 2 ( $n p m 2 a$ and $n p m 2 b)$ genes were recently found to be crucial for egg developmental competence; suppression of $n p m 2 b$ resulted in embryonic arrest before zygotic genome activation (ZGA) in mouse and zebrafish, and npm $2 a$ deficiency in zebrafish led to a complete lack of embryonic development[6]. Further, post-ovulatory ageing induced egg quality defects are associated with low mRNA levels of igf1 (insulin growth factor 1) and beta-tubulin, as well as a small but significant overabundance of keratins 8 and 18, cathepsin Z, and pgs2 (prostaglandin synthase 2)[7,8]. In addition, controlled induction of ovulation by hormonal or photoperiod manipulation negatively 
impacts egg quality in rainbow trout, and the abundance of several genes including apoC1 (apolipoprotein $\mathrm{C} 1$ ), mr-1 (major histocompatibility class 1 related protein), ntan1 (Nterminal asparagine amidase 1), myo1b (myosin 1b), pyc (pyruvate carboxylase), as well as phb2 (prohibitin 2) was found to be significantly different between naturally and artificially induced eggs[9]. Other studies have suggested that genes involved in immune regulation have an impact on egg competence whereby variable abundance of transcripts in the interferon pathway and mhc (major histocompatibility) class genes was demonstrated in eggs of different quality[10,11]. However, despite these results, knowledge on the factors that contribute to the quality of fish eggs remains patchy. Thus, in this study, we carried out a large-scale analysis to compare the transcriptome of eggs of different quality and performed statistical modeling of differentially expressed genes (DEGs) with survival in order to determine if there are common factors that impact egg quality in unrelated wildtype (WT) females that can then serve as markers and/or predictors of developmental competence. We further conducted functional analyses on two candidate genes that were increased in bad quality eggs using the CRISPR/cas9 knockout system and reveal for the first time the essential roles of two new potential maternal-effect genes, otulina (OTU deubiquitinase with linear linkage specificity a) and slc29a1a (solute carrier family 29, member 1a). Our findings provide evidence that even in different quality eggs from unrelated, wildtype couples bred under standard conditions, gene signatures exist in the egg transcriptome, which can be used to predict developmental competence, and that two new potential maternal-effect genes have essential roles in vertebrate reproduction. 


\section{Results}

Transcriptomic differences between good and bad eggs in all samples

Among the 136 clutches of fertilized egg we collected, we selected 16 clutches each

of good and bad quality eggs defined as those with $>93 \%$ and $<38 \%$ survival at $48 \mathrm{hpf}$, respectively, for microarray analysis using a customized chip containing 61,657 annotated sequences of the zebrafish transcriptome. We excluded the sequences of which $80 \%$ of the samples did not have any expression from further analyses, and we identified 31,261 annotated sequences that were expressed in the majority of the samples. Using the GeneSpring software with an FDR $<0.05$ as an exclusion criteria, 66 DEGs that were statistically significant between good and bad quality eggs were revealed. We observed in the heat map showing supervised clustering (Fig. 1a) of the 66 DEGs that a majority of them were upregulated (60 genes, red signal) with only a few genes ( 6 genes) that were decreased (blue signal) in bad quality eggs as compared to good quality eggs. Additional file 1 lists the 66 DEGs including their associated information. Of these 66 genes, 8 were annotated in Ensembl with a unique identifier, but were not found to be associated with any known gene or protein.

\section{Overrepresentation analyses of gene ontological terms of the DEGs}

We submitted the 66 DEGs to functional annotation analyses by gene ontology using two different online programs, DAVID[12] and PANTHER[13], with the entire zebrafish transcriptome as background (Fig. 1b-1c). Among the 66 DEGs submitted, functional terms associated with 55 and 54 annotated genes were identified and therefore classified by the DAVID and PANTHER programs, respectively. In the former analysis, one cluster of terms (enrichment score: 10.13) were enriched from our gene list included intracellular 
$(p=0.00164)$, translation $(p=1.6 E-10)$, and ribosomes ( $p=9.6 E-14)$ (Fig. 1b). In the latter analysis, the DEGs were classified according to biological processes, which included cellular processes, metabolic processes, cell component and biogenesis, biological regulation, response to stimulus, developmental processes, localization, and reproduction (Fig. 1C). In fact, upon inspection of the differentially expressed genes shown in Additional file 1, the ones that underwent the most drastic changes in expression (ribosome production factor 2 homolog (S. cerevisiae) [rpf2], ribosomal protein S27 (isoform 2) [rps27], and U1 spliceosomal RNA [U1] with fold changes of $7.81,1.90$, and $-2.33 /-2.35$, respectively) are associated with translation//ribosomes.

Quantitative real-time polymerase chain reaction ( $q P C R$ ) validation of the DEGs

In order to confirm the results obtained by microarray analysis, another independent method to detect gene expression changes was performed. qPCR was conducted using the same 32 samples that were submitted to microarray analysis and the primers used are listed in Additional file 2. Eight genes that underwent the most drastic changes in microarray analysis were subjected to $\mathrm{qPCR}$, and their biological function as well as the p-value and fold change in the microarray analysis are shown in Additional file 3. qPCR confirmed that the expression of $r p f 2(1.87 \pm 0.33$ vs. $0.48 \pm 0.20, p=0.01)$, spon $1 b$ [spondin $1 b$ ] $(1.61 \pm 0.34$ vs. $0.49 \pm 0.09, p=0.0003), t \operatorname{span} 7 b$ [tetraspanin $7 b$ ] $(1.00 \pm 0.11$ vs. $0.50 \pm 0.08, p=0.001), r p s 27$ $(2.82 \pm 0.18$ vs. $1.66 \pm 0.13, p<0.0001)$, stra13 [stimulated by retinoic acid 13 homolog/centromere protein $\mathrm{X}$ ] $(1.20 \pm 0.09$ vs. $0.87 \pm 0.12, \mathrm{p}=0.03)$, and $r$ tn 4 ip [reticulon 4 interacting protein 1$](1.02 \pm 0.07$ vs. $0.84 \pm 0.04, p=0.03)$ were upregulated in bad quality eggs as compared to good quality eggs, while that of $U 1(21.08 \pm 5.81$ vs. $4.38 \pm 1.28, p=0.009)$ and slc29a1a $(1.04 \pm 0.05$ vs. $1.26 \pm 0.06, p=0.008)$ were increased in bad relative to good 
quality eggs (Fig. 2a-h). Interestingly, despite the statistical significance in the differential regulation of $U 1$ (Fig. $2 \mathrm{~g}$ ), the expression of this gene was regulated in the opposite direction by qPCR as compared to by microarray analysis. In fact, we found that $U 1$ expression was decreased on average by 2.3-fold in bad quality eggs relative to good quality eggs as assessed by microarray, but $\mathrm{QPCR}$ results showed that it was increased by approximately 5-folds in bad as compared to good quality eggs. Regardless of this difference, we found by both microarray and QPCR that the transcript level of all eight genes were differentially regulated.

\section{Couples analysis}

Within the two groups of fertilized eggs, we observed a large variability in the expression of the genes using both detection methods. Upon further inspection, we found that certain couples (\#5,10,33; Additional file 4) consistently produced bad quality eggs ( $\leq 50 \%$ survival at $48 \mathrm{hpf}$ ). Therefore, fertilized eggs harvested at two different periods (1-3 months apart) from these 3 couples ( 6 samples in total) along with samples from 6 random couples that consistently produced good quality eggs were submitted for re-analyses by microarray and qPCR.

\section{Transcriptomic differences by microarray in different couples}

Microarray analysis using the GeneSpring program of the six samples that came from the three couples that consistently produced bad quality eggs revealed 1385 DEGs, and there appeared less variability in transcript levels within each sample group, as shown in the heat map by supervised clustering (Fig. 3a). The complete list of annotated genes is shown in Additional file 5. Similar to the microarray results of all 32 samples, we observed that 
there were far more upregulated genes (1240) in the bad quality eggs relative to good quality eggs (145 genes). Of the 1385 DEGs, 233 could be identified with an Ensembl annotation, but were not found to be associated with any characterized gene or protein. We also observed that the differences in alterations in the transcript levels were much greater in the couples analysis than those detected when all samples were included. For example, there was a 53-fold increase in $t k 2$ [thymidine kinase 2], 25-fold upregulation in $d r d 3$ [dopamine receptor D3], and a 60-fold decrease in the expression of prkcq [protein kinase C, theta] (Additional file 6), while the most differentially regulated genes ( $r p f 2$, spond1b, tspan 7b, and U1) were altered by only 2-7-folds in the former analysis (Additional file 3).

Overrepresentation analyses of gene ontological terms of the DEGs in the couples analysis

In order to get an idea of the functional properties of the 1385 DEGs found by the couples analysis, we submitted this list of genes for gene ontology as before. Of the 1385 DEGs, we were able to classify and identify functional properties of 1151 and 1135 of the genes by the DAVID and PANTHER programs, respectively. The DAVID analysis revealed 5 clusters with enriched terms including ribosome/translation (enrichment score: 2.85; $p=0.02$ ) as well as mitochondria (enrichment score: $3.48 ; p=0.01$ ), flavoprotein (enrichment score: $2.72 ; \mathrm{p}=0.03$ ), methyltransferase (enrichment score: $1.17 ; \mathrm{p}=0.02$ ), and transferase (enrichment score: $0.61 ; p=0.04$ ) (Fig. 3b). The PANTHER analysis revealed that the DEGs were involved in many very similar biological processes as the previous analysis such as cellular processes, metabolic processes, biological regulation, cell component and biogenesis, response to stimulus, localization, developmental processes, multicellular organismal process, immune system, locomotion, and reproduction. Ribosome/translation appeared to be the term that was greatly enriched in all the analyses, suggesting that genes 
that function in this process are especially important in determining egg quality.

qPCR validation of the DEGs in the couples analysis

qPCR was performed to validate the dysregulation of the DEGs that were modified the most in the couples analysis, as listed in Additional file 6 along with their known biological process as well as the p-value and fold change as assessed by microarray. rpf2 and tspan $7 b$ were also found to be drastically dysregulated in the couples analysis, thus, they were resubmitted for $\mathrm{qPCR}$ using just the 12 samples. We confirmed by qPCR that the transcript levels of $t k 2(0.97 \pm 0.41$ vs. $0.0002 \pm 0.0001, p=0.004), d r d 3(3.04 \pm 0.32$ vs. $0.25 \pm 0.09, \mathrm{p}=0.0022), \quad r p f 2(2.82 \pm 0.28$ vs. $0.58 \pm 0.39, \mathrm{p}=0.009), \mathrm{cldn} 23$ [claudin 23] (4.43 \pm 0.42 vs. $0.82 \pm 0.58, p=0.004), \operatorname{tspan} 7 b(1.11 \pm 0.11$ vs. $0.46 \pm 0.15, p=0.03)$, and stra13 $(1.47 \pm 0.17$ vs. $0.61 \pm 0.08, p=0.0022)$ were increased (Fig. 4a-f), while pomt1 [protein-Omannosyltransferase 1$] \quad(0.37 \pm 0.04$ vs. $1.37 \pm 0.20, p=0.0022)$, prkcq $(0.003 \pm 0.001$ vs. $6.02 \pm 1.67, p=0.0022)$, nudt13 [nucleoside diphosphate linked moiety X-type 13] $(0.02 \pm 0.01$ vs. $1.82 \pm 0.60, p=0.0022)$, itih2 [inter-alpha-tryspin inhibitor heavy chain 2] $(0.05 \pm 0.02$ vs. 1.42 $\pm 0.31, \mathrm{p}=0.0022$ ), flvcr1 [feline leukemia subgroup $\mathrm{C}$ cellular receptor family, member 2a] $(0.05 \pm 0.01$ vs. $3.07 \pm 1.02, p=0.0022)$, otulina $(0.10 \pm 0.02$ vs. $0.53 \pm 0.07, p=0.0001)$, and slc29a1a $(1.04 \pm 0.04$ vs. $1.36 \pm 0.13, \mathrm{p}=0.05)$ were downregulated in bad relative to good quality eggs in these 12 samples (Fig. 4g-m).

Functional analysis of otulina and slc29a1a in zebrafish

In order to validate the in vivo significance of some of the DEGs, we performed functional analysis by genetic knockout using the CRISPR/cas9 system on otulina and slc29a1a. RNA-seq data stored in the PhyloFish[14] online database (Additional file 7) as 
well as qPCR analysis for otulina (Fig. 5a) and slc29a1a (Fig. 5b) in different tissues revealed that both of these genes were expressed predominantly in the ovary, which suggest that they play a role in oogenesis and/or reproduction and are thus good candidates for knockdown. One-cell staged embryos were injected with the CRISPR/cas9 guides that targeted either otulina or slc29a1a and allowed to grow to adulthood. Mosaic founder mutant females (FO) were identified by fin clip genotyping and subsequently mated with wild-type (WT) or Dr_vasa:eGFP C3 (hereafter called vasa:eGFP) males, and embryonic development of the F1 fertilized eggs was recorded. Since the mutagenesis efficiency of the CRISPR/cas9 system was very high, as previously described[15,16], the otulina and slc29a1a genes were sufficiently knocked-out even in the transgenic mosaic F0 females. This was evidenced by the substantially lower transcript levels of otulina and slc29a1a in the F1 embryos as compared to those from control WT pairings (Fig. 5c). Thus, the phenotypes of otulina $(n=4)$ and slc29a1a $(n=10)$ mutants could be observed even in the Fo generation. Since none of the mutated genes were transmissible to future generations neither through the male nor the female (ie. only WT F1 progeny survived until adulthood), therefore, all of our observations were obtained from the F0 generation.

We observed that both otulina and slc29a1a mutant-derived eggs had a very low developmental success, defined as the proportion of surviving embryos at $24 \mathrm{hpf}$ to the total number of spawned eggs $(40.0 \pm 6.7 \%$ and $24.8 \pm 6.8 \%$, respectively, vs $74.61 \pm 7.9 \%$ in controls) (Fig. 5d). One spawn of fertilized eggs from the cross between each individual mutant female and a vasa:eGFP male was counted based on its developmental phenotype, described as non-cellularized (lack of cell division), partially cellularized (abnormal cell division), and normal development, as shown in Table 1. As compared to the control embryos that developed normally from 2-24 hpf (Fig. 6a-d), most of the spawned eggs from 
the mutant females were non-cellularized such that they did not undergo any cell division at all throughout the same time period, and they eventually all died by $24 \mathrm{hpf}$ (Fig. 6e-I). However, two of the slc29a1a mutants displayed some heterogeneity in their offspring; while a proportion of the spawn did not develop and did not undergo cell division as observed previously, a number of cells underwent abnormal development characterized by asymmetrical cell division and the appearance of a cell mound on top of an enlarged cytoplasm, which occurred until approximately 4-5 hpf (Fig. $6 \mathrm{~m}$ and $6 \mathrm{n}$ ), after which they began to develop normally albeit slightly slower than their control counterparts (Fig. 6o-6q). To determine if the non-cellularized eggs were unfertilized or were arrested in development immediately after fertilization, we performed PCR genotyping for the gfp gene, which would only come from the vasa:eGFP male and not from the mutant mother that does not harbour any gfp gene. We found that the non-cellularized eggs from both otulina and slc29a1a mutants did not have the gfp gene indicating that they were not fertilized (Fig.6R). These novel findings showed for the first time that otulina and slc29a1a are essential for the developmental competence of eggs, and are therefore crucial maternal-effect genes.

The Wnt pathway is dysregulated following otulina deficiency

In a bid to elucidate a possible mechanism that may govern the function of otulina, we assessed the spawned eggs from otulina-mutant females crossed with WT males for the transcript levels of components of the wnt (wnt3a, tcf3, tcf7, lef1, and $d v / 2$ ) and $t n f / n f-k b$ (nf-kb2, rel, rela, ikkaa, ikkab, and tnfa) pathways. Previous studies have shown that otulina plays a role in these pathways in mammalian models[17-19]. Our findings showed that wnt $3 a$, $t c f 7$, lef1, and $d v / 2$, but not $t c f 3$, were significantly decreased in the otulina mutantderived eggs (Fig. 7a-d), while none of the transcripts belonging to the $t n f / n f-\kappa b$ pathways 
were changed (Additional file 8). Thus, these results highly suggest that otulina plays a role in the wnt pathway in early development, and otulina deficiency leads to loss of developmental success due to dysregulation of wht signaling.

Identification of gene signatures to predict developmental competence by statistical modeling using Partial Least Square (PLS) regression and genetic algorithm

We demonstrated in the previous figures that some of the differentially regulated genes were correlated with survival. However, these findings were based on univariate analysis of individual genes. Thus, we decided to use PLS regression to model the link between transcriptomic data and survival rate. Then, in order to select the best subsets of genes (of both small size and high survival prediction ability), a genetic algorithm was used as it allows the efficient exploration of sets of solutions (here subsets of genes) that are too abundant to be exhaustively explored.

In order to make the selection by genetic algorithm easier and quicker, a preliminary filtering of genes was performed: a correlation test performed on all 31,317 genes eliminated those that did not show any correlation at all to survival, and the redundant genes with highly correlated expressions were grouped together, which left us with 5410 genes for further analysis. Genetic algorithm coupled with PLS was applied to the 5410 remaining genes to search for subsets of genes potentially associated with survival. Two outputs can be expected from this analysis: first by globally exploring the solutions of several runs, it is possible to provide a list of genes which can be considered as potentially related to survival and, second, a more specific study of the solutions of several runs will allow the retrieval of a few candidate signatures of small subsets of complementary genes that we can use for diagnostic purposes. 
We ran the genetic algorithm coupled with PLS 70 times with populations of 500 individuals. We thus obtained 35,000 final solutions. In order to set a frequency threshold to decide which genes can be selected, pseudodata were used: the genetic algorithm was applied using identical conditions as previously mentioned to datasets with randomly permuted survival rates. The 35,000 solutions were evaluated by 10 runs of 2 -fold cross validation (2-FCV), and the average $\mathrm{R}^{2}$ values obtained from the 10 runs were retained as quality criteria for each solution. Hence, to ensure the proposed solutions were relevant, the average 2-FCV $R^{2}$ values obtained on the actual dataset were compared to the ones obtained on the pseudo-datasets with permuted survival rates. Fig. 8a shows that the 2-FCV $R^{2}$ obtained for the final solutions for the actual survival rates were significantly higher than that for the randomized ones ( $p$-value <2.10E-16; Mann-Whitney U-test), thus, the prediction models are relevant. Further, the more often a gene appeared in those final solutions, the more likely it was associated with survival. Hence, if a variable was selected more often in the results obtained from the actual survival rates than from the pseudo survival rates, it may be considered to be potentially related to the phenomenon studied. We therefore compared how often each variable was selected in populations from the actual data and from the randomized data. The results are presented in Fig. 8b. The upper panel displays the selection frequencies of each gene in the final populations of the genetic algorithm applied on the real dataset while the lower panel displays those for the randomized values. These data clearly show that there were no significant peaks in the randomized data as compared to the actual dataset, which suggest that they do not carry biological meaning and can be used as a minimum frequency threshold for gene selection to be considered as biologically relevant. The 95th and 99th percentiles of the distribution of frequencies in the randomized data were used to obtain sets of genes that were the most 
often selected; 156 genes were obtained with a threshold of $5 \%$ and 29 genes with a threshold of $1 \%$, the latter of which is listed in Table 2. Among these 29 genes, 10 of them were DEGs found by our microarray analyses (boldfaced, italicized).

Subsequently, the same results can be used to identify a gene signature that only retains small subsets of genes that are the most relevant for diagnostic purposes. Towards this goal, all 35000 final solutions were evaluated by 10 runs of 2 -fold cross validation (2FCV), and the average $R^{2}$ values obtained from the 10 runs were retained as quality criteria for each solution. However, genetic algorithms are powerful methods that may be misleading, thus, the two best solutions were selected as good compromises between quality of the prediction and parsimony of the model (Table 3). The average 2-FCV $R^{2}$ of solutions 1 and 2 were 0.9771 and 0.9678 , respectively using 7 and 8 genes respectively (with 5 common genes between them, italicized).

Thus, these findings demonstrated the presence of strong gene signatures, which were statistically robust both in terms of reproducibility and validation by pseudo-data, to link gene expression to the survival rate of eggs in our transcriptomic data.

\section{Discussion}

In this study, we analyzed the maternally-provided transcriptome in fertilized zebrafish eggs at the one-cell stage in order to determine expressional differences between bad and good quality eggs that could impact egg quality in unrelated wildtype females. Despite the haphazard causes of decreased egg competence, we still found by microarray and validated by an independent method of transcript quantitation, qPCR, a large number of DEGs that were represented predominantly by those that function in ribosome and translation processes. Thus, there appears to be substantial differences in the maternally- 
inherited transcriptome between good and bad quality eggs that may have an impact on egg competence and subsequent embryonic development, and may serve as markers or predictors of egg quality.

When all the samples were taken into consideration, only 66 DEGs were found between good and bad quality eggs, which is a relatively low number as compared to other studies. In fact, it must be reiterated that all of the couples that were mated and produced clutches were wildtype, without any particular treatment, and mostly unrelated. Thus, there may have been multiple natural causes behind the decline in quality of the eggs from the different mothers, such as nutrition, density, age of parents, delay from last spawn, and genetics just to name a few $[1,20,21]$. Despite the heterogeneous potential causes of varying egg quality, 66 DEGs were identified of which 7 genes were verified independently by qPCR. These genes all play different cellular roles: $r p f 2[22]$ is a ribosome assembly protein that recruit 5 S rRNA and ribosomal proteins into nascent large ribosome subunits; rps27.2[23] is a structural component of the $40 S$ small ribosome subunit; spond1b[24] encodes a protein secreted by floor plate cells during embryogenesis that localizes to the central spinal canal and has neuroregulatory functions; $r \operatorname{tn} 4 i p[25]$ is a mitochondrial protein present in neurons and astrocytes; tspan $7 b[26]$ is a cell surface receptor signaling molecule that functions in embryonic development; stra13[27] has roles in DNA repair and kinetochore assembly; and slc29a1a[28] is transmembrane glycoprotein that mediates the cellular uptake of nucleosides. Their distinct roles in the cell highlight the fact that embryonic survival is based on many different cellular processes and suggest that they may serve as candidate markers of egg quality among unrelated wildtype females in larger populations.

A recent paper demonstrated that the transcriptome in unfertilized zebrafish eggs from different mothers can be quite variable while it was more uniform within clutches, 
which suggests that mother-related differences in the transcriptome may potentially be associated with egg quality and subsequent development of the embryo[29]. To this end, we performed a couples analysis in which we compared clutches of eggs from 3 couples that consistently produced bad quality eggs to those that frequently gave good quality eggs in order to eliminate some of the environmental effects on maternal health and egg competence. In this narrowed-down analysis using only 12 clutches of eggs ( 6 each of good and bad quality), we revealed more than 1300 DEGs with less variability between samples than in the first analysis (Figure 3). We also found that the 4 DEGs that were common in the two analyses, $r p f 2$, slc29a1a, tspan $7 b$, and stra13 were more homogeneously expressed as there was less variability between samples. These results suggest that despite the heterogeneous causes, many common mechanisms contribute to egg quality among unrelated couples that consistently produce bad quality eggs, and these can serve as good markers for egg competence and hence embryonic survival.

With regard to the functional characteristics of the DEGs in the study using all samples, overrepresentation analyses of the $\mathrm{GO}$ terms by both DAVID and PANTHER programs found that genes that function in ribosome and translation were enriched, which are consistent with previous findings that showed that translation-related transcripts were also differentially expressed in sea bass eggs of different quality[30]. Interestingly, the findings in this study correlate with our previous proteomic study which also demonstrated significant dysregulation of proteins with functions in protein synthesis in zebrafish eggs of varying quality[31]. In the proteomic study, peptides that function in protein synthesis were upregulated in both good and bad quality eggs, which suggest a general dysregulation of the system. In this study, rpf2 and rps 27.2 were found by microarray and confirmed by qPCR to be increased in bad quality eggs (Fig.2A, 4C, and 2D, respectively). Both of these genes 
encode proteins that function in ribosomes; rpf2 is an assembly factor and rps27.2 is a structural component of the $40 \mathrm{~S}$ small ribosome subunit as mentioned above. A similar finding was demonstrated in a previous study that investigated the transcriptome of eggs after natural and controlled ovulation in rainbow trout (Oncorhynchus mykiss); it was revealed that $r p / 24$, which is a structural component of the large ribosome subunit, was more abundant in the latter which had higher mortality[9]. Thus, it appears that in eggs of bad quality, there is an apparent increase in ribosome biogenesis. This seems somewhat contradictory due to the fact that most bad quality eggs eventually die and an accumulation in ribosomes is usually a sign of increased cell proliferation and growth[32]. It is well-known that ribosome biogenesis deficiency often leads to an impairment in cell growth and to cell death while elevated ribosomal function results in increased cell cycle progression and proliferation[33]. Thus, it is possible that the increased ribosomal content and presumably elevated translation that were found in bad quality eggs may reflect dysregulated cell cycle progression and cell growth, which in fact may lead to premature cell death as shown by pathological models in which loss of cell cycle and cell death regulators lead to disease[34,35]. On the other hand, it is also a possibility that ribosome biogenesis dysregulation may be an effect and not cause of loss of embryonic survival; an unknown mechanism that operates during oogenesis may cause the accumulation of ribosomal content in bad quality eggs and its abundance reflects a dysfunction of the mechanism. Whichever the case, dysregulation of the protein synthesis process appears to be at both the transcript and protein levels.

In general, the expression data in the couples analysis were less heterogeneous with less spread within each group, and the differences in gene expression between the two groups were larger than those observed in the first analysis (Fig. 4a-m and Additional file 6 
vs. Fig. 2a-h and Additional file 3, respectively). Literature search showed that most of these genes have known functions: $t k 2[36]$ is a deoxyribonucleoside kinase that is required for mitochondrial DNA synthesis; $d r d 3[37]$ is dopamine receptor which is associated with cognitive, emotional, and endocrine functions; cldn23[38] is an integral membrane protein that maintains cell polarity and signal transductions; nudt13[39] is hydrolase and its function is also largely unknown; itih2[40] is a serine protease inhibitor that carries hyaluronan in plasma; flvcr1[41] is a heme transporter that has a critical role in erythropoiesis by protecting developing erythroid cells from heme toxicity; pomt1[42] is an 0 mannosyltransferase that is a component of many polysaccharides and glycoproteins; prkcq[43] is a serine- and threonine-specific protein kinase that is important for T-cell activation; and otulina[44] is a predicted deubiquitinase also called fam105ba. qPCR confirmed the differential expression of these genes in bad quality eggs relative to good quality eggs (Fig. 4a-m). From these results, it appears that there is a general dysfunction of multiple cellular processes when only couples that consistently produce bad quality eggs are taken into account, as opposed to a general population of random couples. Thus, the mechanisms that are involved in egg quality may be different depending on the couple; infrequent production of bad quality eggs in a random, unrelated population may involve dysfunction of ribosome/translation processes while there may be a general dysregulation of multiple cellular processes in frequent producers of bad quality eggs. Our results also suggest that within a random population of unrelated females, some common elements that impact egg competence exist, thus, a portfolio of gene profiles can be established for use as markers of egg quality which would be extremely useful in identification of reproductively successful females.

In order to determine if panels or sets of genes that together may be used to predict 
or associated with survival exist, we decided to use a statistical approach which combined PLS and genetic algorithm. Obtaining a gene signature to predict the survival rate is valuable and of practical interest since identification of a set of genes that correlates with the rate of survival can open up avenues for understanding the biological phenomena to explain egg quality and for future biotechnological applications. Our first analysis exhaustively explored the data and provided us with a list of 29 genes that were all considered to be highly related to survival (Table 2). In addition, a second analysis that was performed in order to retain only the genes that were the most pertinent in prediction of developmental competence revealed two solutions that included a set of 7 and 8 genes, respectively (Table 3), that were selected as offering good compromises between quality of the prediction and parsimony of the model genes. There were 5 common genes (italicized) between the two solutions, which could be manipulated for diagnostic purposes. Thus, our statistical modeling approach demonstrated that gene signatures could be obtained from transcriptomic data that could predict developmental competence in fertilized eggs, which would have practical interests.

In an effort to investigate the functional significance of some of the DEGs, we created CRISPR/cas9 knockouts of otulina and sc29a1a due to their ovary-specific localization, respectively (Fig.5A-5B). Notably, we demonstrated for the first time that deficiency in each of these genes render females subfertile, with complete lack of development in the spawned eggs, which were shown to be unfertilized (Fig. 6r). Thus, our data suggested that otulina and slc29a1a may play roles that contribute to the factors important for fertilization. otulina is predicted to encode for a deubiquitinase, which removes methionine 1-linked ubiquitin chains, of the OTU family in zebrafish, and substratebound otulin in mammals has been shown to associate with the linear ubiquitin chain assembly complex (LUBAC). This ubiquitination-deubiquitination system is a key regulator of 
important signaling pathways, including Wnt, TNF- $\alpha$, and NF-kb. The otulin gene, the mammalian homologue, has been previously shown to be involved in early development in mice since a functionally-disruptive gene mutation results in embryonic lethality due to perturbed Wnt signaling and angiogenesis[17]. In fact, it is known that Wnt signaling plays a major role in gonad differentiation in some fish species[45-47]. Further, otulin has also been shown to be a key factor in regulating inflammation and immunity through it's modulatory role in the TNF- $\alpha$ and NF-kb pathways[18,19]. It is known that inflammatory signaling is an essential part of early embryonic development since many of these components are part of the maternally-inherited repertoire of transcripts, and the TNF- $\alpha$ and NF-kb pathways play important roles in embryonic hematopoietic stem and progenitor cell production as well as body patterning/specification[48-51]. Our results showed that there were significant decreases in the transcript levels of several wnt components including wnt $3 a, t c f 7$, lef1, and $d v / 2$ (Fig. 7), while none of the transcripts belonging to the tnf/nf-kb pathways showed any changes. Thus, otulina deficiency may contribute to subfertility in zebrafish via dysregulation of wnt signaling, in line with our previous study that showed that the wnt pathway was disturbed at the protein level in bad quality eggs and with the known function of wht in development[31,52,53].

On the other hand, slc29a1a is predicted to encode for an equilibrative nucleoside transporter. In mammals, it was shown that slc29a1 transports adenosine, which is a potent cellular metabolite that functions in cyclic AMP pathways and also acts directly as a vasoactive mediator, into fetal cells and has implications in fetal endothelial functions such that its dysfunction can lead to human pregnancy-related problems such as gestational diabetes, intrauterine growth restriction, and pre-eclampsia[54-56]. In addition, s/c29 homologues in chicken play important roles in rhythm and conduction in developing 
embryonic hearts via the ERK/MAP (extracellular signal regulated kinase/mitogen activated protein) pathways[57]. However, the function of slc29a1 in fish is still unknown since these species usually undergo external fertilization and embryonic growth. Further investigations into their physiological functions are warranted.

\section{Conclusions}

In this report, transcriptomic profiling of zebrafish fertilized eggs of different quality demonstrated that: 1) dysregulation of the protein synthesis process may be a mechanism behind the reduction in egg quality; 2) gene signatures may exist in the maternally-inherited transcriptome that could be used to predict development competence; and 3) together with the use of CRISPR-cas9 knockout mutants, we clearly showed for the first time that otulina and slc29a1a are essential for the developmental competence of zebrafish eggs and could be novel maternal-effect genes, which would broaden our understanding of the mechanisms that contribute to egg quality.

\section{Methods}

Fish husbandry and sample collection

Wildtype zebrafish (Danio rerio) of the $A B$ strain were maintained in a central filtration recirculating system with a $12 \mathrm{hr}$ light/dark cycle in the INRA LPGP fish facility (Rennes, France). Individual couple pairing was performed by placing a male and a female overnight in a tank with a partition for separation, and in the morning, the divider was removed after which the female released her eggs to be fertilized by the male. One hundred and thirty-six clutches of fertilized zebrafish eggs at the one-cell stage from 58 families (Additional file 4) were harvested and divided into two parts. One part was flash-frozen in 
TRI reagent (Sigma-Aldrich, St. Louis, MO) and stored at $-80^{\circ} \mathrm{C}$ for molecular biology analyses. The other part was cultured in modified Yamamoto's embryo solution (17 mM $\mathrm{NaCl}, 400 \mu \mathrm{M} \mathrm{KCl}, 270 \mu \mathrm{M} \mathrm{CaCl} 2.2 \mathrm{H}_{2} \mathrm{O}, 650 \mu \mathrm{M} \mathrm{MgSO}_{4} .7 \mathrm{H}_{2} \mathrm{O}, 0.1 \mu \mathrm{l} / \mathrm{ml}$ of methylene blue) and monitored for up to 48 hours, and the number of survivors was counted at 8,24 , and 48 hpf. Good quality eggs were defined as embryos that had a very high survival rate (>93\%) at $48 \mathrm{hpf}$ and bad quality eggs were those that suffered a very low survival rate $(<38 \%)$ at 48 hpf. All procedures of fish husbandry and sample collection were in accordance with the guidelines set by the French and European regulations on animal welfare. Protocols were approved by the Rennes ethical committee for animal research (CREEA) under approval no. R2012-JB-01.

\section{RNA extraction}

Total RNA of the pooled clutches was extracted using TRI reagent according to the manufacturer's protocol, and RNA quality and purity were assessed using the Agilent Nano RNA 6000 assay kit and 2100 Bioanalyzer (Agilent Technologies, Santa Clara, CA). All samples were confirmed to have an RIN (RNA integrity number) of 9-10 which are generally accepted as reflecting very good quality RNA.

\section{Microarray analysis}

Zebrafish gene expression profiling was conducted using an Agilent 8x60K highdensity oligonucleotide microarray (GPL24500). Labeling and hybridization steps were performed following the Agilent "One-Color Microarray-Based Gene Expression Analysis (Low Input Quick Amp labeling)" protocol. Briefly, for each sample, 150 ng of total RNA was amplified and labeled using Cy3-CTP. Yield (>825 ng CRNA) and specific activity ( $>6$ pmol of 
Cy3 per $\mu \mathrm{g}$ of CRNA) of Cy3-cRNA produced were checked with the NanoDrop 2000 spectrophotometer (Thermo Fisher Scientific, Waltham, MA). 600 ng of Cy3-cRNA was fragmented and hybridized on a sub-array. Hybridization was carried out for 17 hours at $65^{\circ} \mathrm{C}$ in a rotating hybridization oven prior to washing and scanning with an Agilent Scanner (Agilent DNA Microarray Scanner, Agilent Technologies, Massy, France) using the standard parameters for a gene expression $8 \times 60 \mathrm{~K}$ oligoarray ( $3 \mu \mathrm{m}$ and $20 \mathrm{bits}$ ). Data were then obtained with the Agilent Feature Extraction software (10.7.3.1) according to the appropriate GE protocol (GE1_107_Sep09) and imported into GeneSpring GX software (Agilent Technologies) for analysis. The data were first normalized by median centering, logged, and then subjected to differential gene expression analysis. All data available in the Gene Expression Omnibus database under accession GSE109073.

Gene Ontology (GO) analysis

The differentially expressed genes (DEGs) that were found to have a false discovery rate $(F D R)<0.05$ and a corrected $p$-value $<0.05$ by microarray were subjected to overrepresentation analyses using DAVID version 6.7 (https://david.ncifcrf.gov/[12] and PANTHER (www.pantherdb.org/[13] online programs using Ensembl gene identifiers to elucidate enriched terms. The DAVID analyses were conducted using the Functional Annotation Tool based on GOTERM_BP_ALL terms with Benjamini multiple test correction and a FDR<0.05. For the PANTHER analyses, an overrepresentation test, version 10.0 released 2015-05-15, using the GO-Slim Biological Process annotation data set and a Bonferroni correction for multiple testing set at $p<0.05$ was performed. 
Reverse transcription polymerase chain reaction and quantitative real-time $P C R(q P C R)$

One $\mu \mathrm{g}$ of RNA was used as template for synthesis of cDNA using the Maxima First Strand cDNA Synthesis Kit (Thermo Fisher Scientific) as per the manufacturer's protocol. The CDNA samples were then diluted 20 -fold and subjected to qPCR using the primers listed in Additional file 2. Primers were designed using the online program Primer3 (http://primer3.ut.ee) and extended across an intron when possible to eliminate the contribution from genomic DNA. qPCR was performed in triplicate using the GoTaq qPCR Mastermix kit (Promega, Madison, WI), which utilizes carboxy-X-rhodamine (CXR) as the reference fluorochrome, using the following cycling condition: $95^{\circ} \mathrm{C}$ for 10 seconds and $60^{\circ} \mathrm{C}$ for 30 seconds for 40 cycles. The data were collected with the Applied Biosystems StepOnePlus apparatus (Foster City, CA) and quantitation of the samples was conducted using standard curves. LSM couples member 14B (Ism14b), prefoldin subunit 2 (pfdn2), and ring finger protein $8(r n f 8)$ had the most stable expression in the microarray dataset and were thus used as internal controls for qPCR. Further, $18 \mathrm{~S}$ rRNA, beta-actin (bact), and elongation factor 1 alpha $(E F 1 \propto)$ were also used as internal controls for qPCR[58]. The geometric means of all 6 genes were calculated and for normalization of the data quantity.

\section{CrispR-cas9 genetic knockout}

CRISPR/cas9 guide RNA (gRNA) were designed using the ZiFiT Targeter online software (version 4.2)[59,60] and were made against 3 targets within each gene to generate large genomic deletions, ranging from $130-1500$ base pairs, that span exons which allow the formation of non-functional proteins. Nucleotide sequences containing the gRNA were ordered, annealed together, and cloned into the DR274 plasmid. In vitro transcription of the gRNA from the T7 initiation site was performed using the Maxiscript T7 kit (Applied 
Biosystems), and their purity and integrity were assessed using the Agilent RNA 6000 Nano Assay kit and 2100 Bioanalyzer (Agilent Technologies). Zebrafish embryos at the one-cell stage were micro-injected with approximately 30-40 pg of each CRISPR/cas9 guide along with 8-9 $\mathrm{nM}$ of purified cas9 protein (a generous gift from Dr. Anne de Cian from the National Museum of Natural History in Paris, France). The embryos were allowed to grow to adulthood, and genotyped using fin clip and PCR that detected the deleted regions. The PCR bands of the mutants were then sent for sequencing to verify the deletion. Once confirmed, the mutant females were mated with wildtype males to produce F1 embryos, whose phenotypes were subsequently recorded. Images were captured with a Nikon AZ100 microscope and DS-Ri1 camera (Tokyo, Japan).

Genotyping by $P C R$

Fin clips harvested from animals under anesthesia ( $0.1 \%$ phenoxyethanol) and $\mathrm{F} 1$ eggs from females crossed with vasa:eGFP males were lysed with 5\% chelex containing $100 \mu \mathrm{g}$ of proteinase $\mathrm{K}$ at $55^{\circ} \mathrm{C}$ for $2 \mathrm{hrs}$ and then $99^{\circ} \mathrm{C}$ for 10 minutes. The extracted DNA was subjected to PCR using the AccuPrime system (Promega) for slc29a1a, Advantage 2 system for nucleoplasmin $2 b(n p m 2 b)$, and Jumpstart Taq polymerase (Sigma-Aldrich, St. Louis, MO) for otulina and vasa:eGFP. The primers are listed in Additional file 2.

\section{Statistical analyses}

Statistical analysis of the difference in the expression of each gene between bad and good quality embryos was performed using either Mann-Whitney's U-test or Student's t-test after determination of normality of distribution using the Anderson-Darling test. All statistical determinations were conducted using GraphPad Prism version 7 (La Jolla, CA). 
Data are presented as mean \pm standard error (SEM). A p-value $<0.05$ was considered as statistically significant.

Analyses by Partial Least Squares (PLS) regression and genetic algorithm

Elimination of the least relevant genes from subsequent analyses was initially performed. First, a correlation test with a $10 \%$ p-value threshold between each gene expression and survival rate was conducted. Subsequently, a Pearson correlation coefficient was computed for the expression of each pair of genes. Clusters of genes with pairwise correlations higher than 0.95 were considered as redundant, and only the genes with the highest correlation to survival were selected for subsequent analyses.

Genetic algorithm (GA) was performed whereby Tpop (500) random solutions were generated by first choosing a random number $(p)$ of genes between 1 and Pmax (20) then randomly drawing $p$ genes from the candidate genes[61]. PLS regression, which combines the expression levels of the selected genes through linear combinations in order to obtain an estimate of the survival rate, was then applied using the squared Pearson correlation coefficient between the actual survival rates and the estimates as the criterion to evaluate the quality of each proposed subset of genes[62]. A two-fold cross-validation (2-FCV) was always performed to avoid over-fitting, which consisted of applying the PLS model on half of the observations and quantifying the quality of this model by applying it to the other half. This was performed twice by exchanging the application and prediction of the two halves. Once the criterion was computed for each candidate solution, solutions were ranked according to their value, where a high 2-FCV $\mathrm{R}^{2}$ reflected a higher rank. Then, selection was applied by associating each solution with a selection probability that was proportional to its quality rank. In this way, the best solutions were selected for subsequent generations 
whereas suboptimal solutions were likely eliminated[63]. The selected solutions underwent modifications through two operators: mutation and cross-over. Mutation consisted of randomly adding, removing or replacing a gene in the solution. $p m \%(90 \%)$ of the solutions underwent mutation. Cross-over consisted of randomly splitting each of two solutions into two subsets of genes and exchanging one subset between them to obtain new gene combinations. $p c \%$ (50\%) of the solutions underwent cross-over. After mutation and crossover, the new solutions were evaluated again with the same process and selection was applied again. This process was repeated through Ngene (200) generations. The solutions selected in the final generation were submitted to extensive evaluation using ten runs of 2FCV. The average $R^{2}$ obtained for each solution was used as the final criterion to select the best subset of genes.

To challenge the relevancy of the obtained solutions, the same genetic algorithm was applied on randomized datasets, which were obtained by randomly permuting the survival rates of the different observations. First, it is expected that if a gene is linked to the survival process it is likely to often appear in the final solutions. In order to quantify the frequency, the distribution of the number of selections of each gene in the randomized datasets was computed, and only genes with number of selections in the actual data higher than the $95^{\text {th }}$ or $99^{\text {th }}$ percentile of that in the randomized distribution were considered as relevant. Second, the quality of solutions, defined as the distribution of the average 2-FCV $R^{2}$ of the final solutions, obtained on the actual and randomized datasets were also compared. The relationship between gene expression and survival rate was considered significant when the actual $R^{2}$ values were significantly higher than the $R^{2}$ values of the randomized dataset. To compare their distributions, a Mann-Whitney test was used. 


\section{List of abbreviations}

2-FCV: 2-fold cross validation

cldn23: claudin 23

DEGs: differentially expressed genes

drd3: dopamine receptor D3

FDR: false discovery rate

flvcr1: feline leukemia subgroup C cellular receptor family, member $2 a$

gfp: blue fluorescent protein

hpf: hours post-fertilization

itih2: inter-alpha-tryspin inhibitor heavy chain 2

MBT: mid-blastula transition

$n p m 2 a$ and $n p m 2 b:$ nucleoplasmin $2 \mathrm{a} / \mathrm{b}$

nudt13: nucleoside diphosphate linked moiety X-type 13

otulina: OTU deubiquitinase with linear linkage specificity a, fam105ba

PLS: partial least square regression

pomt1: protein-O-mannosyltransferase 1

prkcq: protein kinase $\mathrm{C}$, theta

qPCR: quantitative real-time polymerase chain reaction

RNA-seq: RNA sequencing

rpf2: ribosome production factor 2 homolog (S. cerevisiae)

rps27: ribosomal protein S27 (isoform 2)

rtn4ip: reticulon 4 interacting protein 1

slc29a1a: solute carrier family 29 , member $1 a$

spon $1 b$ : spondin $1 b$ 
stra13: stimulated by retinoic acid 13 homolog/centromere protein $\mathrm{X}$

$t k 2:$ thymidine kinase 2

tspan $7 \mathrm{~b}$ : tetraspanin $7 \mathrm{~b}$

U1: U1 spliceosomal RNA

WT: wildtype

ZGA: zygotic genome activation

\section{Declarations}

Ethics approval and consent to participate. Not applicable.

Consent for publication. Not applicable.

Availability of data and material. The datasets generated and materials used in the current study are available upon request and in Gene Expression Omnibus (https://www.ncbi.nlm.nih.gov/geo/) database under accession GSE109073.

Competing interests. The authors declare that there are no competing interests.

Funding. This work was supported the French National Research Agency (ANR) under grant agreement ANR-13-BSV7-0015-Maternal Legacy to JB.

Authors contributions. CTC performed most of the experiments and data analyses as well as preparation of the manuscript; TN monitored and harvested the zebrafish embryos and extracted the RNA for microarray; ALC performed the microarray and subsequent data analyses; AP was responsible for animal care and husbandry; LJ facilitated the project through scientific discussions; CR performed the statistical modeling experiment and subsequent data analyses; and JB conceived the study and was responsible for overseeing the project, scientific discussions, and preparation of the manuscript. All authors read and approved the final manuscript.

Acknowledgements 
bioRxiv preprint doi: https://doi.org/10.1101/286815; this version posted March 23, 2018. The copyright holder for this preprint (which was not certified by peer review) is the author/funder. All rights reserved. No reuse allowed without permission.

We would like to thank all of the support staff and other members of the Fish Physiology and Genomics Institute of Rennes (INRA) for their technical aid. We are very grateful to Jean-Jacques Lareyre (INRA/LPGP) for his kind gift of the Dr_vasa:eGFP C3 zebrafish line. 


\section{References}

1. Bobe J, Labbe C. Egg and sperm quality in fish. Gen Comp Endocrinol. 2010;165:535-48.

2. Pelegri F. Maternal factors in zebrafish development. Dev Dyn. 2003;228:535-54.

3. Pellettieri J, Reinke V, Kim SK, Seydoux G. Coordinate activation of maternal protein degradation during the egg-to-embryo transition in C. elegans. Dev Cell. 2003;5:451-62.

4. Wagner DS, Dosch R, Mintzer KA, Wiemelt AP, Mullins MC. Maternal control of development at the midblastula transition and beyond: mutants from the zebrafish II. Dev Cell. 2004;6:781-90.

5. Tadros W, Lipshitz HD. The maternal-to-zygotic transition: a play in two acts. Development. 2009;136:3033-42.

6. Bouleau A, Desvignes T, Traverso JM, Nguyen T, Chesnel F, Fauvel C, et al. Maternally inherited npm2 mRNA is crucial for egg developmental competence in zebrafish. Biol Reprod. 2014;91:43.

7. Aegerter S, Jalabert B, Bobe J. Messenger RNA stockpile of cyclin B, insulin-like growth factor I, insulin-like growth factor II, insulin-like growth factor receptor Ib, and p53 in the rainbow trout oocyte in relation with developmental competence. Mol Reprod Dev. $2004 ; 67: 127-35$.

8. Aegerter S, Jalabert B, Bobe J. Large scale real-time PCR analysis of mRNA abundance in rainbow trout eggs in relationship with egg quality and post-ovulatory ageing. Mol Reprod Dev. $2005 ; 72: 377-85$.

9. Bonnet E, Fostier A, Bobe J. Characterization of rainbow trout egg quality: a case study using four different breeding protocols, with emphasis on the incidence of embryonic malformations. Theriogenology. 2007;67:786-94.

10. Mommens M, Fernandes JM, Tollefsen KE, Johnston IA, Babiak I. Profiling of the 
embryonic Atlantic halibut (Hippoglossus hippoglossus L.) transcriptome reveals maternal transcripts as potential markers of embryo quality. BMC Genomics. 2014;15:829.

11. Rise ML, Nash GW, Hall JR, Booman M, Hori TS, Trippel EA, et al. Variation in embryonic mortality and maternal transcript expression among Atlantic cod (Gadus morhua) broodstock: a functional genomics study. Mar Genomics. 2014;18 Pt A:3-20.

12. Huang da W, Sherman BT, Lempicki RA. Systematic and integrative analysis of large gene lists using DAVID bioinformatics resources. Nat Protoc. 2009;4:44-57.

13. Mi H, Poudel S, Muruganujan A, Casagrande JT, Thomas PD. PANTHER version 10: expanded protein families and functions, and analysis tools. Nucleic Acids Res. 2016;44:D336-42.

14. Pasquier J, Cabau C, Nguyen T, Jouanno E, Severac D, Braasch I, et al. Gene evolution and gene expression after whole genome duplication in fish: the PhyloFish database. BMC Genomics. 2016;17:368.

15. Auer TO, Duroure K, De Cian A, Concordet JP, Del Bene F. Highly efficient CRISPR/Cas9mediated knock-in in zebrafish by homology-independent DNA repair. Genome Res. $2014 ; 24: 142-53$.

16. Gagnon JA, Valen E, Thyme SB, Huang P, Akhmetova L, Pauli A, et al. Efficient mutagenesis by Cas9 protein-mediated oligonucleotide insertion and large-scale assessment of single-guide RNAs. PLoS One. 2014;9:e98186.

17. Rivkin E, Almeida SM, Ceccarelli DF, Juang Y-C, MacLean TA, Srikumar T, et al. The linear ubiquitin-specific deubiquitinase gumby regulates angiogenesis. Nature. England; $2013 ; 498: 318-24$.

18. Damgaard RB, Walker JA, Marco-Casanova P, Morgan NV, Titheradge HL, Elliott PR, et al. The Deubiquitinase OTULIN Is an Essential Negative Regulator of Inflammation and 
Autoimmunity. Cell. 2016. p. 1215-1230.e20.

19. Elliott PR, Komander D. Regulation of Met1-linked polyubiquitin signalling by the deubiquitinase OTULIN. FEBS J. 2016;283:39-53.

20. Ribas L, Valdivieso A, Díaz N, Piferrer F. Appropriate rearing density in domesticated zebrafish to avoid masculinization: links with the stress response. J. Exp. Biol. $2017 ; 220: 1056-64$.

21. Ribas L, Liew WC, Díaz N, Sreenivasan R, Orbán L, Piferrer F. Heat-induced masculinization in domesticated zebrafish is family-specific and yields a set of different gonadal transcriptomes. Proc. Natl. Acad. Sci. 2017;114:E941-50.

22. Kharde S, Calvino FR, Gumiero A, Wild K, Sinning I. The structure of Rpf2-Rrs1 explains its role in ribosome biogenesis. Nucleic Acids Res. 2015;43:7083-95.

23. Wang R, Yoshida K, Toki T, Sawada T, Uechi T, Okuno Y, et al. Loss of function mutations in RPL27 and RPS27 identified by whole-exome sequencing in Diamond-Blackfan anaemia. Br J Haematol. 2015;168:854-64.

24. Higashijima S, Nose a, Eguchi G, Hotta Y, Okamoto H. Mindin/F-spondin family: novel ECM proteins expressed in the zebrafish embryonic axis. Dev. Biol. 1997;192:211-27.

25. Hu WH, Hausmann ON, Yan MS, Walters WM, Wong PK, Bethea JR. Identification and characterization of a novel Nogo-interacting mitochondrial protein (NIMP). J Neurochem. $2002 ; 81: 36-45$.

26. Berditchevski F. Complexes of tetraspanins with integrins: more than meets the eye. J Cell Sci. 2001;114:4143-51.

27. Osman F, Whitby MC. Emerging roles for centromere-associated proteins in DNA repair and genetic recombination. Biochem Soc Trans. 2013;41:1726-30.

28. Young JD. The SLC28 (CNT) and SLC29 (ENT) nucleoside transporter families: a 30-year 
collaborative odyssey. Biochem Soc Trans. 2016;44:869-76.

29. Rauwerda H, Wackers P, Pagano JF, de Jong M, Ensink W, Dekker R, et al. MotherSpecific Signature in the Maternal Transcriptome Composition of Mature, Unfertilized Zebrafish Eggs. PLoS One. 2016;11:e0147151.

30. Żarski D, Nguyen T, Le Cam A, Montfort J, Dutto G, Vidal MO, et al. Transcriptomic Profiling of Egg Quality in Sea Bass (Dicentrarchus labrax) Sheds Light on Genes Involved in Ubiquitination and Translation. Mar. Biotechnol. 2017;19:102-15.

31. Yilmaz O, Patinote A, Thao T, Nguyen V, Com E, Lavigne R, et al. Scrambled eggs?: Proteomic portraits and novel biomarkers of egg quality in zebrafish ( Danio rerio ) To cite this version?]: HAL Id]: hal-01640969 Scrambled eggs?: Proteomic portraits and novel biomarkers of egg quality in zebrafish ( Danio rerio ). 2017;1-24.

32. Thomas G. An encore for ribosome biogenesis in the control of cell proliferation. Nat Cell Biol. 2000;2:E71-2.

33. Plaks V, Gershon E, Zeisel A, Jacob-Hirsch J, Neeman M, Winterhager E, et al. Blastocyst implantation failure relates to impaired translational machinery gene expression. Reproduction. 2014;148:87-98.

34. Montanaro L, Trere D, Derenzini M. Changes in ribosome biogenesis may induce cancer by down-regulating the cell tumor suppressor potential. Biochim Biophys Acta. 2012;1825:101-10.

35. Polzikov M, Yakovenko S, Voznesenskaya J, Troshina M, Zatsepina O. Overexpression of ribosomal RNA in cumulus cells of patients with polycystic ovary syndrome. J Assist Reprod Genet. 2012;29:1141-5.

36. Sun R, Eriksson S, Wang L. Mitochondrial thymidine kinase 2 but not deoxyguanosine kinase is up-regulated during the stationary growth phase of cultured cells. Nucleosides 
Nucleotides Nucleic Acids. 2014;33:282-6.

37. Ahlgren-Beckendorf JA, Levant B. Signaling mechanisms of the D3 dopamine receptor. J Recept Signal Transduct Res. 2004;24:117-30.

38. Katoh M. CLDN23 gene, frequently down-regulated in intestinal-type gastric cancer, is a novel member of CLAUDIN gene family. Int J Mol Med. 2003;11:683-9.

39. Nguyen VN, Park A, Xu A, Srouji JR, Brenner SE, Kirsch JF. Substrate specificity characterization for eight putative nudix hydrolases. Evaluation of criteria for substrate identification within the Nudix family. Proteins. 84:1810-22.

40. Geisert RD, Ashworth MD, Malayer JR. Expression of inter-alpha-trypsin inhibitor heavy chains in endometrium of cyclic and pregnant gilts. Reproduction. 2003;126:621-7.

41. Khan AA, Quigley JG. Control of intracellular heme levels: heme transporters and heme oxygenases. Biochim Biophys Acta. 2011;1813:668-82.

42. Ragni E, Lommel M, Moro M, Crosti M, Lavazza C, Parazzi V, et al. Protein Omannosylation is crucial for human mesencyhmal stem cells fate. Cell Mol Life Sci. 73:44558.

43. Meller N, Altman A, Isakov N. New perspectives on PKCtheta, a member of the novel subfamily of protein kinase C. Stem Cells. 1998;16:178-92.

44. Grou CP, Pinto MP, Mendes A V, Domingues P, Azevedo JE. The de novo synthesis of ubiquitin: identification of deubiquitinases acting on ubiquitin precursors. Sci Rep. 5:12836.

45. Nicol B, Guiguen Y. Expression profiling of Wnt signaling genes during gonadal differentiation and gametogenesis in rainbow trout. Sex Dev. Switzerland; 2011;5:318-29.

46. Nicol B, Yano A, Jouanno E, Guerin A, Fostier A, Guiguen Y. Follistatin is an early player in rainbow trout ovarian differentiation and is both colocalized with aromatase and regulated by the wnt pathway. Sex Dev. Switzerland; 2013;7:267-76. 
47. Sreenivasan R, Jiang J, Wang X, Bartfai R, Kwan HY, Christoffels A, et al. Gonad differentiation in zebrafish is regulated by the canonical Wnt signaling pathway. Biol. Reprod. United States; 2014;90:45.

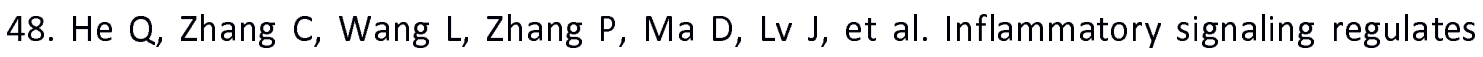
hematopoietic stem and progenitor cell emergence in vertebrates. Blood. United States; $2015 ; 125: 1098-106$.

49. Li Y, Esain V, Teng L, Xu J, Kwan W, Frost IM, et al. Inflammatory signaling regulates embryonic hematopoietic stem and progenitor cell production. Genes Dev. United States; $2014 ; 28: 2597-612$.

50. Lee MT, Bonneau AR, Takacs CM, Bazzini AA, DiVito KR, Fleming ES, et al. Nanog, Pou5f1 and SoxB1 activate zygotic gene expression during the maternal-to-zygotic transition. Nature. 2013;503:360-4.

51. Maddirevula S, Anuppalle M, Huh T-L, Kim SH, Rhee M. Rnf11-like is a novel component of NF-kappaB signaling, governing the posterior patterning in the zebrafish embryos. Biochem. Biophys. Res. Commun. United States; 2012;422:602-6.

52. Huang YL, Anvarian Z, Doderlein G, Acebron SP, Niehrs C. Maternal Wnt/STOP signaling promotes cell division during early Xenopus embryogenesis. Proc Natl Acad Sci U S A. $112: 5732-7$.

53. Nojima H, Shimizu T, Kim CH, Yabe T, Bae YK, Muraoka O, et al. Genetic evidence for involvement of maternally derived Wnt canonical signaling in dorsal determination in zebrafish. Mech. Dev. 2004;121:371-86.

54. Farías M, Puebla C, Westermeier F, Jo MJ, Pastor-Anglada M, Casanello P, et al. Nitric oxide reduces SLC29A1 promoter activity and adenosine transport involving transcription factor complex hCHOP-C/EBP $\alpha$ in human umbilical vein endothelial cells from gestational 
diabetes. Cardiovasc. Res. 2010;86:45-54.

55. Casanello P, Escudero C, Sobrevia L. Equilibrative nucleoside (ENTs) and cationic amino acid (CATs) transporters: implications in foetal endothelial dysfunction in human pregnancy diseases. Curr. Vasc. Pharmacol. United Arab Emirates; 2007;5:69-84.

56. Escudero C, Casanello P, Sobrevia L. Human equilibrative nucleoside transporters 1 and 2 may be differentially modulated by $\mathrm{A} 2 \mathrm{~B}$ adenosine receptors in placenta microvascular endothelial cells from pre-eclampsia. Placenta. Netherlands; 2008;29:816-25.

57. Robin E, Sabourin J, Marcillac F, Raddatz E. Involvement of CD73, equilibrative nucleoside transporters and inosine in rhythm and conduction disturbances mediated by adenosine $\mathrm{A} 1$ and $\mathrm{A} 2 \mathrm{~A}$ receptors in the developing heart. J. Mol. Cell. Cardiol. England; $2013 ; 63: 14-25$.

58. McCurley AT, Callard G V. Characterization of housekeeping genes in zebrafish: malefemale differences and effects of tissue type, developmental stage and chemical treatment. BMC Mol Biol. 2008;9:102.

59. Sander JD, Zaback P, Joung JK, Voytas DF, Dobbs D. Zinc Finger Targeter (ZiFiT): an engineered zinc finger/target site design tool. Nucleic Acids Res. England; 2007;35:W599605.

60. Sander JD, Maeder ML, Reyon D, Voytas DF, Joung JK, Dobbs D. ZiFiT (Zinc Finger Targeter): an updated zinc finger engineering tool. Nucleic Acids Res. England; 2010;38:W462-8.

61. Goldberg DE, Holland JH. Genetic Algorithms and Machine Learning. Mach. Learn. 1988;3:95-9.

62. Wold H. Partial Least Squares. In: Kotz S, Johnson NL, editors. Encycl. Stat. Sci. volume 6. New York: Wiley; 2006. p. 581-91. 
63. BHANDARI D, MURTHY CA, PAL SK. GENETIC ALGORITHM WITH ELITIST MODEL AND ITS CONVERGENCE. Int. J. Pattern Recognit. Artif. Intell. 1996;10:731-47.

64. Kimmel CB, Ballard WW, Kimmel SR, Ullmann B, Schilling TF. Stages of embryonic development of the zebrafish. Dev Dyn. 1995;203:253-310. 


\section{Figure Legends}

Fig. 1 a: Heat map showing supervised clustering of the 66 differentially expressed genes (DEGs) between good and bad quality eggs from 32 clutches of fertilized zebrafish eggs. Yellow signal denotes upregulation, blue signal denotes downregulation, and black defines no change in expression. b: Gene ontology analysis using the DAVID online program of the 55 DEGs with known information. The enriched term and Benjamini value are shown. c: Functional classification of 54 DEGs with known function using the PANTHER online program. The biological processes associated with the DEGs and Benjamini value are shown. A Benjamini value of less than 0.05 was considered as statistically significant.

Fig. 2: Validation of the microarray data by performance of quantitative real-time PCR (qPCR). Eight genes, including (a) rpf2, (b) spon1b, (c) tspan 7b, (d) rps27.2, (e) stra13, (f) rtn4ip1, (g) U1, and (h) slc29a1a were subjected to qPCR using the primers listed in Additional file 2, whereby LSM couples member 14B (Ism14b), prefoldin subunit 2 (pfdn2), and ring finger protein 8 ( $r n f 8)$ as well as 18S rRNA, beta-actin (bact), and elongation factor 1 alpha (EF1 $\alpha$ ) were used as internal controls. * p-value $\leq 0.05, * *$ p-value $\leq 0.01, * * * p$-value $\leq 0.001, * * * *$ p-value $<<0.001$

Fig. 3 a: Heat map showing supervised clustering of the 1385 differentially expressed genes (DEGs) between good and bad quality eggs from 16 clutches of fertilized zebrafish eggs in the couples analysis. Red signal denotes upregulation, blue signal denotes downregulation, and black defines no change in expression. b: Gene ontology analysis of the 1151 DEGs with known information using the DAVID online program. The enriched term and Benjamini value are shown. c: Functional classification of the 1135 DEGs with known function using the 
PANTHER online program. The biological processes associated with the DEGs and Benjamini value are shown. A Benjamini value of less than 0.05 was considered as statistically significant.

Fig. 4: Validation of the microarray data by performance of quantitative real-time PCR (qPCR). The six genes upregulated, (a) $t k 2$, (b) $d r d 3$, (c) rpf2, (d) cldn23, (e) tspan $7 b$, (f) stra13, and seven genes downregulated, (g) pomt1, (h) prkcq, (i) nudt13, (j) itih2, (k) flvcr1, (I) otulina, (m) slc29a1a, in bad quality eggs were subjected to qPCR using the primers listed in Additional file 2. LSM couples member 14B (Ism14b), prefoldin subunit 2 (pfdn2), and ring finger protein 8 (rnf8) as well as 18S rRNA, beta-actin (bact), and elongation factor 1 alpha $(E F 1 \alpha)$ were used as internal controls. * $\mathrm{p}$-value $\leq 0.05,{ }^{* *} \mathrm{p}$-value $\leq 0.01, * * * \mathrm{p}$-value $\leq 0.001$

Fig. 5: Tissue localization of otulina (a) and s/c29a1a (b) based on qPCR assays. c: Expression level of otulina and s/c29a1a in spawned eggs from mutant females mated with WT males as assessed by qPCR. 18S rRNA, beta-actin (bact), and elongation factor 1 alpha (EF1 $\propto$ ) were used as internal controls, and experiments performed in triplicate. d: Developmental success in terms of survival rate of embryos at 24 hours post-fertilization (hpf) from otulinaand s/c29a1a-deficient mutant females mated with WT males. $\mathrm{N}=4$ for otulina and $\mathrm{N}=10$ for slc29a1a, at least three spawns from each mutant.

Fig. 6: Representative images showing the development between 0-24 hours postfertilization (hpf) of F1 embryos from wildtype control (a-d), otulina-deficient (e-h), and slc29a1a-deficient (i-q) females. In the control eggs, the embryos were at 64-cell (a), oblong (b), shield (c), and 24-somite (d) stages according to Kimmel et al[64]. Eggs from otulina and 
slc29a1a mutant females were non-developing and did not under any cell division (e-l). Some eggs from two slc29a1a mutant females were developing abnormally (m-q). (a, e, i, m) $=$ images taken at $2 \mathrm{hpf} ;(\mathrm{b}, \mathrm{f}, \mathrm{j}, \mathrm{n})=$ images taken at $4 \mathrm{hpf} ;(\mathrm{c}, \mathrm{g}, \mathrm{k}, \mathrm{o})=$ images taken at 6 hpf; $(p)=$ image taken at $8 \mathrm{hpf} ;(\mathrm{d}, \mathrm{h}, \mathrm{l}, \mathrm{q})=$ images taken at $24 \mathrm{hpf}$. The arrow demonstrates a partially cellularized blastodisc that was sitting atop an enlarged syncytium. Scale bars denote $500 \mu \mathrm{m}$. r: PCR genotyping for nucleoplasmin $2 b(n p m 2 b)$ and vasa:eGFP in spawned eggs from WT, otulina-, and slc29a1a-mutant females crossed with vasa:eGFP males to detect fertilization of the eggs. Std $=1 \mathrm{~kb}$ ladder; Con $=$ WT female crossed with vasa:eGFP male.

Fig. 7: Evaluation of the expression levels of wnt3a (a), tcf7 (b), lef1 (c), and $d v / 2$ (d) in spawned eggs from otulina-deficient mutant females mated with WT males as assessed by qPCR. $18 \mathrm{~S}$ rRNA, beta-actin (bact), and elongation factor 1 alpha (EF1 $\alpha)$ were used as internal controls, and experiments performed in triplicate. $\mathrm{N}=4$, at least three spawns from each mutant.

Fig. 8 a: The average 2 -fold cross validation $R^{2}$ values obtained from the actual dataset were compared to the ones obtained from the pseudo-datasets with permuted survival rates. $b$ : The frequency that each variable was selected in populations from the actual data and from the randomized data. The 95th and 99th percentiles of the distribution of frequencies in the randomized data were used to obtain sets of genes that were the most often selected.

\section{Additional Files}

Additional file 1: The complete list of the 66 DEGs including the gene description, Ensembl 
annotation, corrected p-value, and fold change. Analysis was performed with the GeneSpring GX program.

Additional file 2: Sequences of the primer pairs that were used in this study.

Additional file 3: List of differentially expressed genes (DEGs) in bad quality eggs as compared to good quality eggs that were the most modified among the 66 DEGs found by microarray analysis.

Additional file 4: Detailed information on the couples that were mated to produce fertilized eggs and the clutches that were harvested in this study. The number of eggs in each clutch was counted and between 40-60 eggs were followed for up to 48 hours post-fertilization (hpf). The number of surviving embryos were counted at 8,24 , and $48 \mathrm{hpf}$, and the survival rate was accordingly calculated at each timepoint. * The clutches of bad quality eggs that were used for the couples analysis.

Additional file 5: The complete list of the 1385 DEGs including the gene description, Ensembl annotation, corrected $\mathrm{p}$-value, and fold change from the couples analysis. Analysis was performed with the GeneSpring GX program

Additional file 6: List of 13 differentially expressed genes (DEGs) in bad quality eggs as compared to good quality eggs that were the most modified among the 1385 DEGs found in the couples analysis by microarray.

Additional file 7: Tissue localization of (a) otulina and (b) slc29a1a transcripts by RNA-seq retrieved from the Phylofish online database.

Additional file 8: Evaluation by $\mathrm{qPCR}$ for transcripts of wnt, tnf, and $n f-k b$ pathways in otulina mutant-derived eggs. Transcript levels of (a) tcf3, (b) tnfa, (c) $i k k a a,(d), n f-k b 2,(\mathrm{e})$ rel, and (f) rela were investigated by qPCR. 
Table 1 (please refer to pg. 10): Penetrance of fam105ba and s/c29a1a mutant phenotypes

\begin{tabular}{|c|c|c|c|c|}
\hline \multirow[b]{3}{*}{ fam105ba-1 } & \multirow{2}{*}{$\begin{array}{c}\text { Total } \\
\text { number } \\
\text { of } \\
\text { embryos }\end{array}$} & \multicolumn{2}{|c|}{ Embryos with defects } & \multirow[b]{2}{*}{$\begin{array}{l}\text { Normal } \\
\text { embryos }\end{array}$} \\
\hline & & $\begin{array}{c}\text { Non- } \\
\text { cellularized }\end{array}$ & $\begin{array}{c}\text { Partially } \\
\text { cellularized }\end{array}$ & \\
\hline & 210 & 163 & & 47 \\
\hline fam $105 b a-2$ & 213 & 172 & & 41 \\
\hline fam $105 b a-3$ & 92 & 53 & & 39 \\
\hline fam $105 b a-4$ & 116 & 110 & & 6 \\
\hline slc29a1a-1 & 104 & 104 & & 0 \\
\hline slc29a1a-2 & 100 & 88 & & 12 \\
\hline slc29a1a-3 & 660 & 450 & & 210 \\
\hline slc29a1a-4 & 451 & 439 & & 12 \\
\hline slc29a1a-5 & 245 & 150 & & 95 \\
\hline slc29a1a-6 & 152 & 138 & & 14 \\
\hline slc29a1a-7 & 361 & 252 & & 110 \\
\hline slc29a1a-8 & 80 & 71 & & 9 \\
\hline slc29a1a-9 & 85 & 9 & 48 & 28 \\
\hline slc29a1a-10 & 370 & 153 & 24 & 193 \\
\hline
\end{tabular}

Penetrance of otulina and s/c29a1a mutant phenotypes in F1 eggs between crosses of otulina or slc29a1a mutant females and WT males. The graph demonstrates representative data from a single spawn from each mutant female. ${ }^{\dagger}$ Embryos did not develop at all (Fig. 6E$6 \mathrm{~L}$ ). ${ }^{\ddagger}$ Embryos had a partially cellularized blastodisc that was sitting atop an enlarged syncytium (arrow in Fig. 6N). 
Table 2 (please refer to pg. 13): List of 29 genes that are associated with survival.

\begin{tabular}{|c|c|}
\hline ENSEMBL gene annotation & Gene name \\
\hline ENSDARG00000090871 & Si:dkey-210j14.4 \\
\hline ENSDARG00000076419 & Si:dkeyp-117b11.2 \\
\hline ENSDARG00000079255 & Zgc:174935 \\
\hline ENSDARG00000031366 & Reticulon 4 interacting protein 1 \\
\hline ENSDARG00000006982 & muscle segment homeobox $\mathrm{D}$ \\
\hline ENSDARG00000071553 & Zgc:171500 \\
\hline ENSDARG00000070898 / ENSDARG00000092291 & Si:ch211-262h13.3 / Si:ch211-281g2.3 \\
\hline ENSDARG00000075318 & Solute carrier family 16 (monocarboxylic acid transporters), member 6a \\
\hline ENSDARG00000063295 & Myosin, heavy polypeptide 9a, non-muscle \\
\hline ENSDARG00000082140/ENSDARG00000082017 & U1 spliceosomalRNA \\
\hline ENSDARG00000089078 & Collagen, type XXIII, alpha 1 \\
\hline ENSDARG00000017820 & Polymerase (RNA) III (DNA directed) polypeptide D \\
\hline ENSDARG00000024687 & Polymerase (RNA) III (DNA directed) polypeptide G \\
\hline ENSDARG00000089422 & CABZ01087562.1 \\
\hline ENSDARG00000056563 & Peroxisome proliferative activated receptor, gamma, coactivator 1 , beta \\
\hline ENSDARG00000076498 & Golgi integral membrane protein $4 a$ \\
\hline ENSDARG00000069425 & Heat shock factor binding protein $1 a$ \\
\hline ENSDARG00000090804 & G protein-coupled receptor $155 a$ \\
\hline ENSDARG00000075434 & RNA 2,3,-cyclic phosphate and 5,-OH ligase \\
\hline ENSDARG00000096436 & Si:dkey-118j18.4 \\
\hline ENSDARG00000089677 & CABZ01117603.1 \\
\hline ENSDARG00000095796 & Si:dkey-87o1.2 \\
\hline ENSDARG00000004898 & Zona pellucida glycoprotein 2 , like 2 \\
\hline ENSDARG00000020149 & Acyl-Coenzyme A oxidase-like \\
\hline ENSDARG00000027738 & Si:ch211-13c6.2 \\
\hline ENSDARG00000080245 & $5 S$ ribosomal RNA \\
\hline ENSDARG00000058445 & Protein disulfide isomerase-like, testis expressed \\
\hline ENSDARG00000078785 & Transmembrane protein 258 \\
\hline ENSDARG00000093926 / ENSDARG00000095522 & Si:dkey-71b5.2/Si:dkey-71b5.3 \\
\hline
\end{tabular}

The 29 genes that were selected from the exhaustive analysis by Partial Least Square (PLS) regression and genetic algorithm. The 10 genes that were differentially regulated in our microarray dataset are boldfaced and italicized. 
Table 3 (please refer to pg. 13): Two solutions from the parsimonic prediction model.

\begin{tabular}{|c|c|}
\hline ENSEMBL gene ref & Gene name \\
\hline \multicolumn{2}{|l|}{ Solution 1} \\
\hline ENSDARG00000079255 & Zgc:174935 \\
\hline ENSDARG00000089677 & CABZ01117603.1 \\
\hline ENSDARG00000090871 & Si:dkey-210j14.4 \\
\hline ENSDARG00000076419 & Si:dkeyp-117b11.2 \\
\hline ENSDARG00000017820 & polymerase (RNA) III (DNA directed) polypeptide $D$ \\
\hline ENSDARG00000086485 & novel protein coding gene \\
\hline ENSDARG00000020054 & aldehyde oxidase 1 \\
\hline \multicolumn{2}{|l|}{ Solution 2} \\
\hline ENSDARG00000079255 & Zgc:174935 \\
\hline ENSDARG00000089677 & CABZ01117603.1 \\
\hline ENSDARG00000090871 & Si:dkey-210j14.4 \\
\hline ENSDARG00000076419 & Si:dkeyp-117b11.2 \\
\hline ENSDARG00000017820 & polymerase (RNA) III (DNA directed) polypeptide $D$ \\
\hline ENSDARG00000016855 & Splicing factor $3 b$, subunit 5 \\
\hline ENSDARG00000088305 & CABZ01072929.1 \\
\hline ENSDARG00000087431 & Zgc:173962 \\
\hline
\end{tabular}

Two solutions containing 7 and 8 genes that were selected from the parsimonic model by Partial Least Square (PLS) regression and genetic algorithm. The 5 common genes between the two solutions are italicized. 


\section{Figure 1}

a

bioRxiv preprint doi: https://doi.org/10.1101/286815; this version posted March 23, 2018. The copyright holder for this preprint (which was not certified by peer review) is the author/funder. All rights reserved. No reuse allowed without permission.

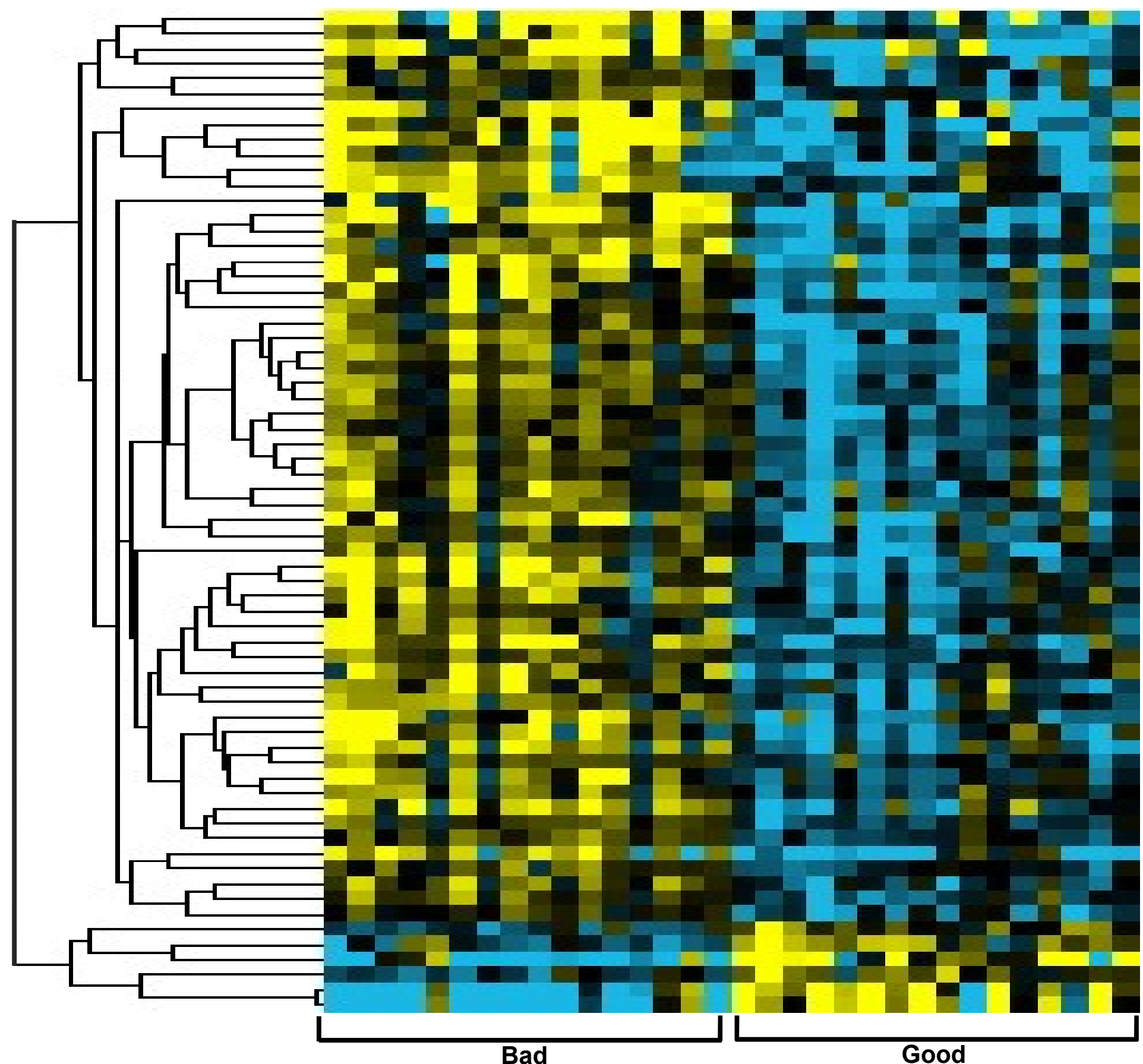

b

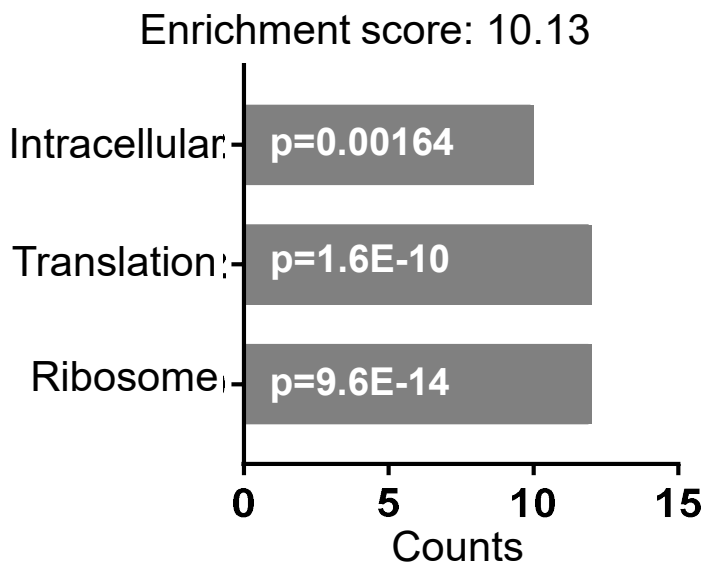

C

Biological regulation (4) Response to stimulus (4)

Cell component organization and biogenesis (8)

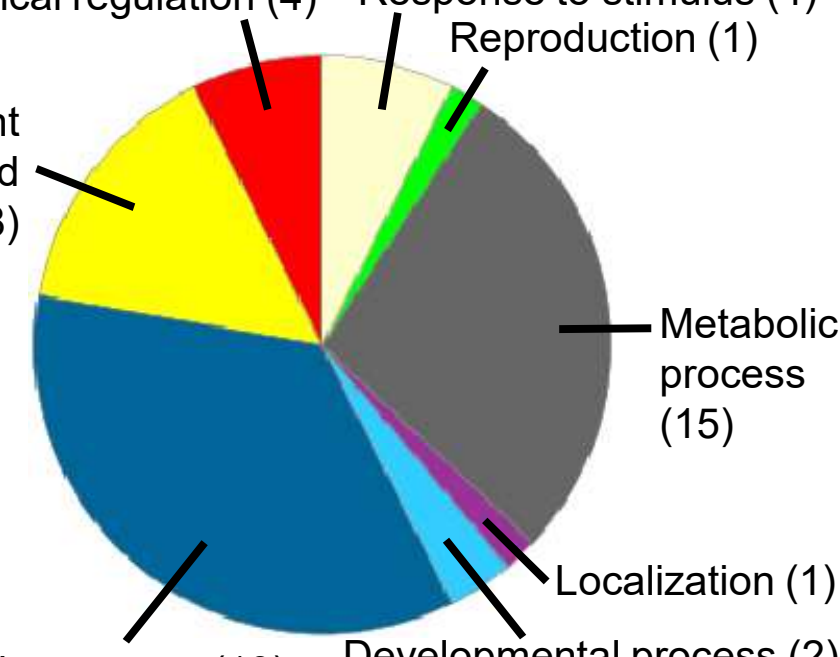

Cellular process (19) Developmental process (2) 
Figure 2

bioRxiv preprint doi: https://doi.org/10.1101/286815; this version posted March 23, 2018. The copyright holder for this preprint (which was not a certified by peer review) is the author/funder. All rights reserved. No reuse allowed without permission.
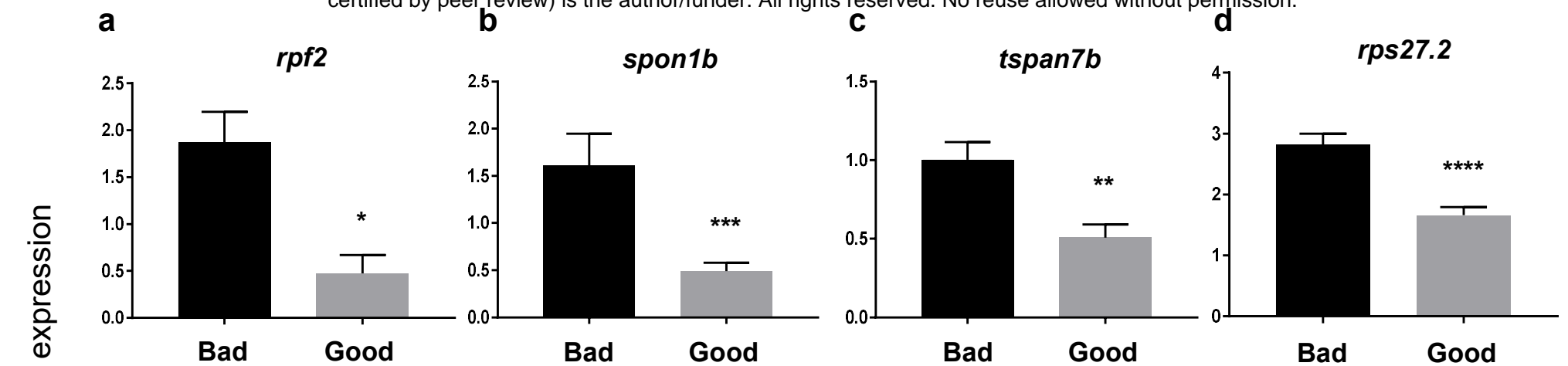

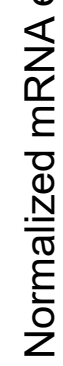
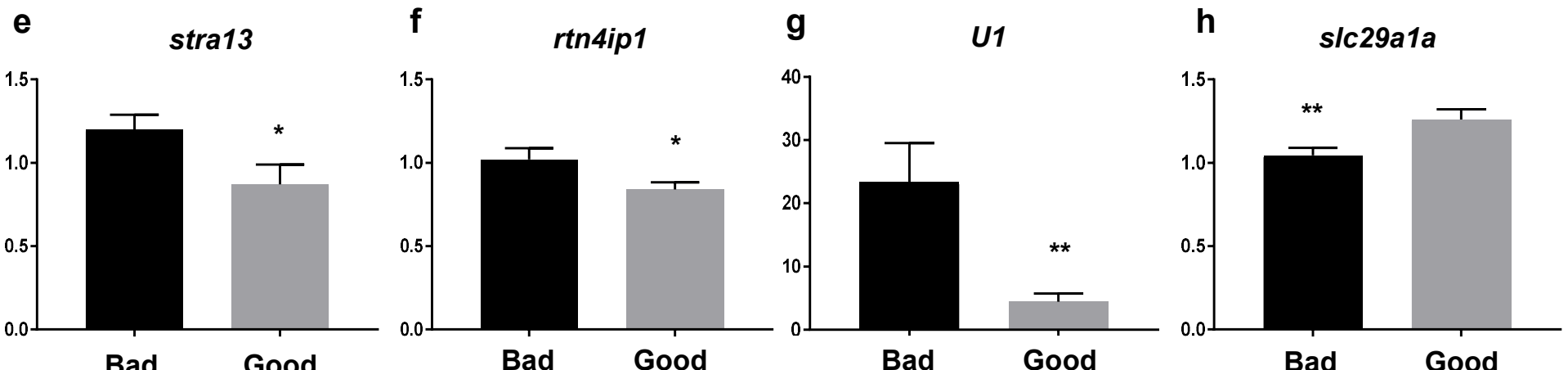

Bad

Bad

Good

Bad

Good

Bad

Good 


\section{Figure 3}

bioRxiv preprint doi: https://doi.org/10.1101/286815; this version posted March 23, 2018. The copyright holder for this preprint (which was not

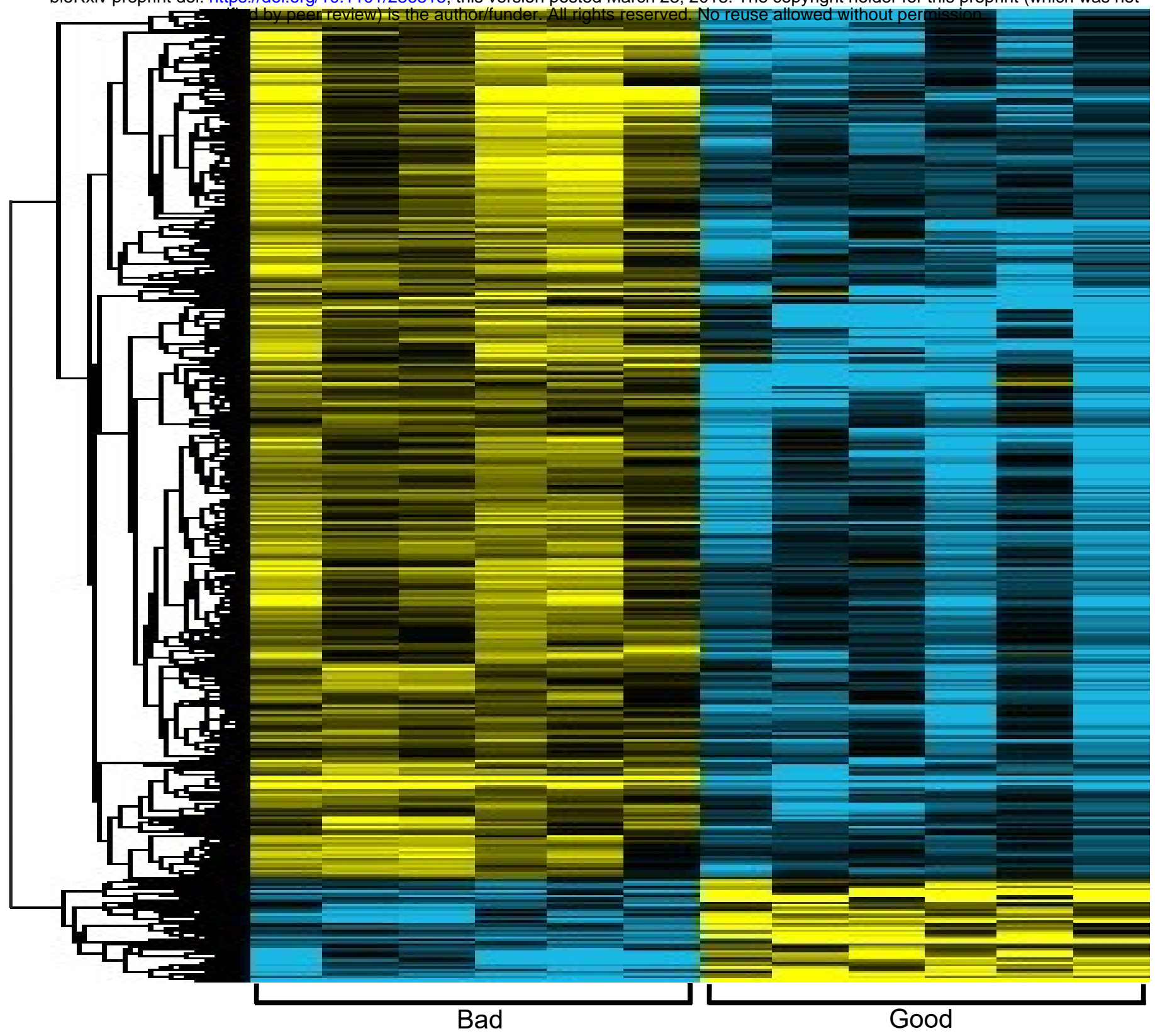

b

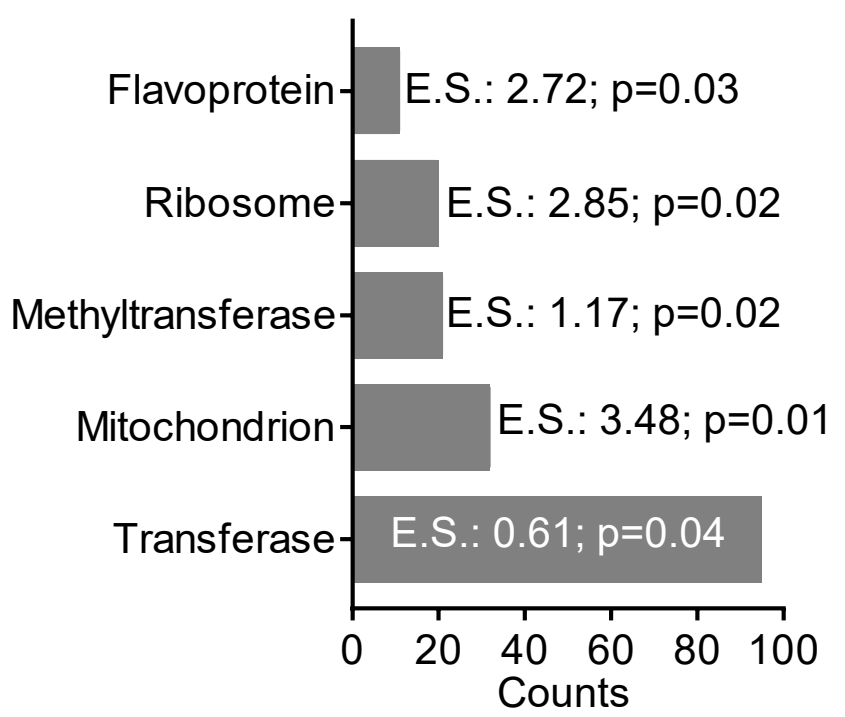

C

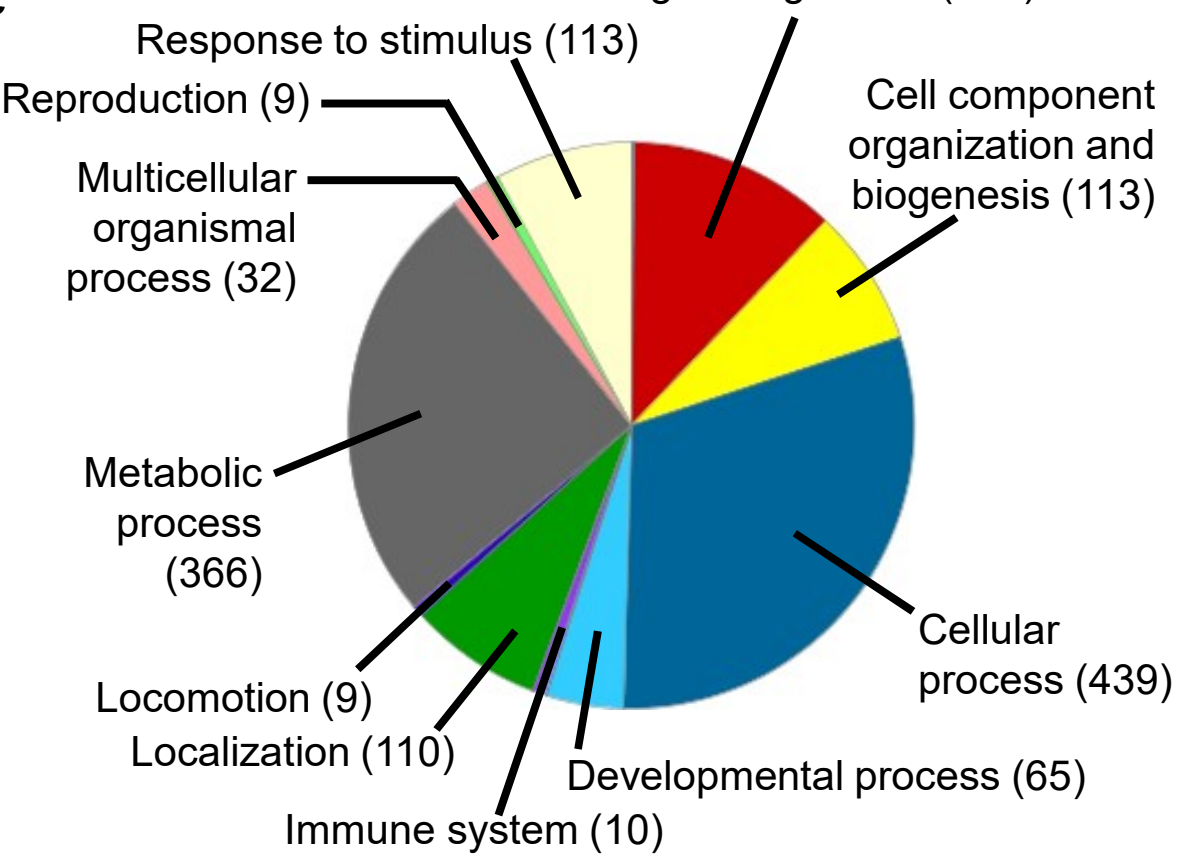


Figure 4

bioRxiv preprint doi: https://doi.org/10.1101/286815; this version posted March 23, 2018. The copyright holder for this preprint (which was not certified by peer review) is the author/funder. All rights reserved. No reuse allowed without permission.

a

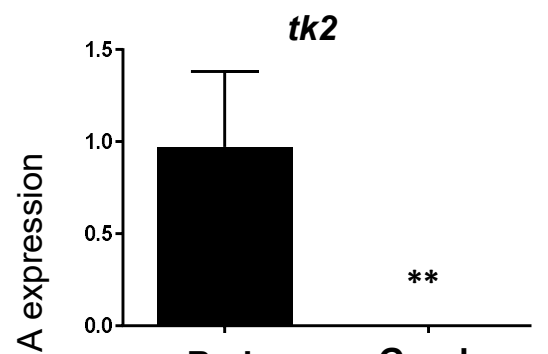

Bad

d

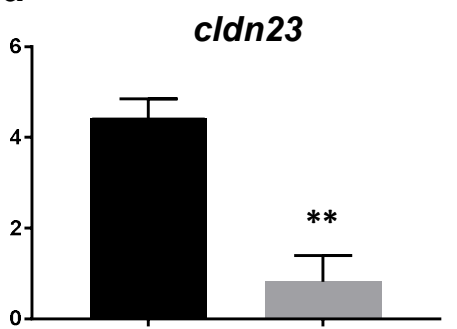

Bad b

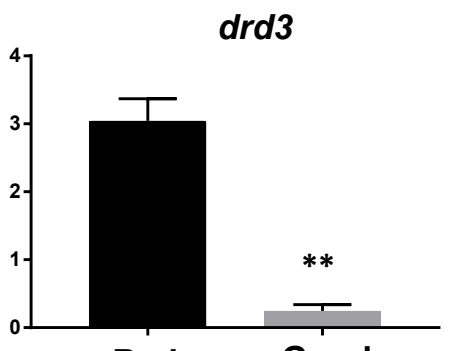

Bad

e

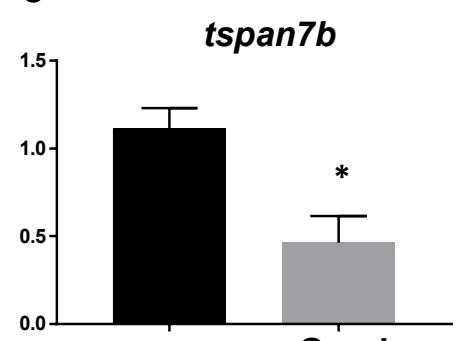

Bad

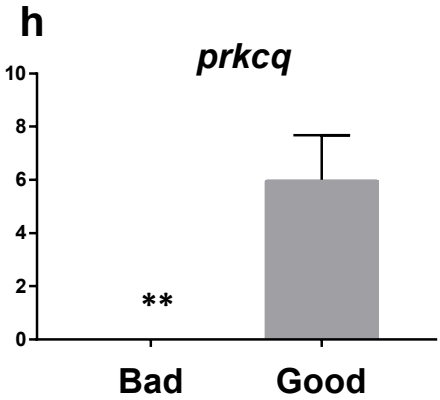

Bad

잠

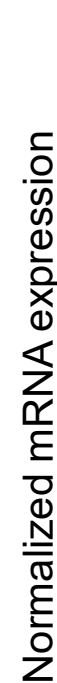

g
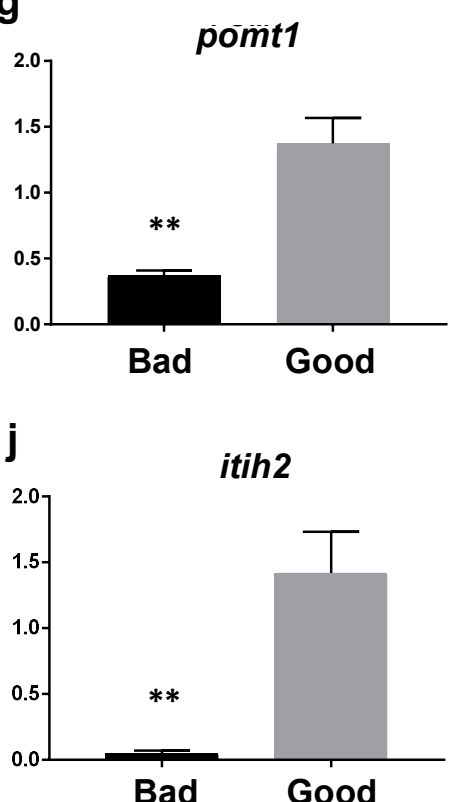

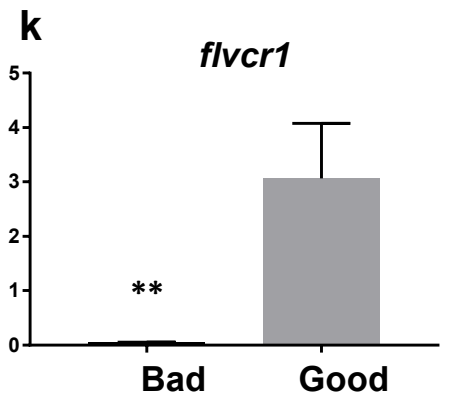

C

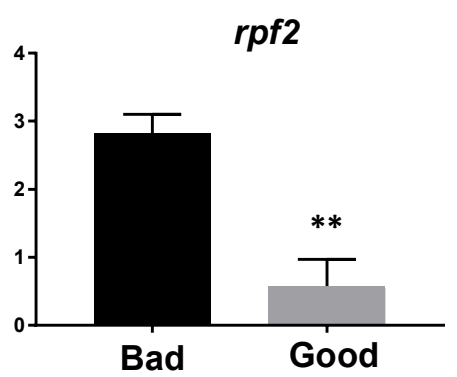

f

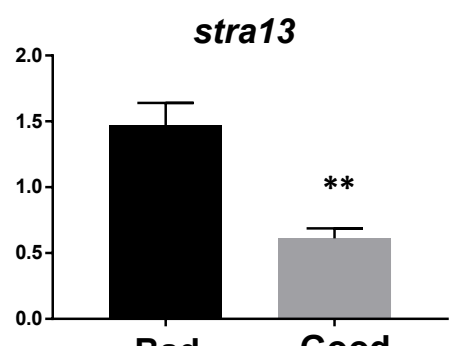

Bad
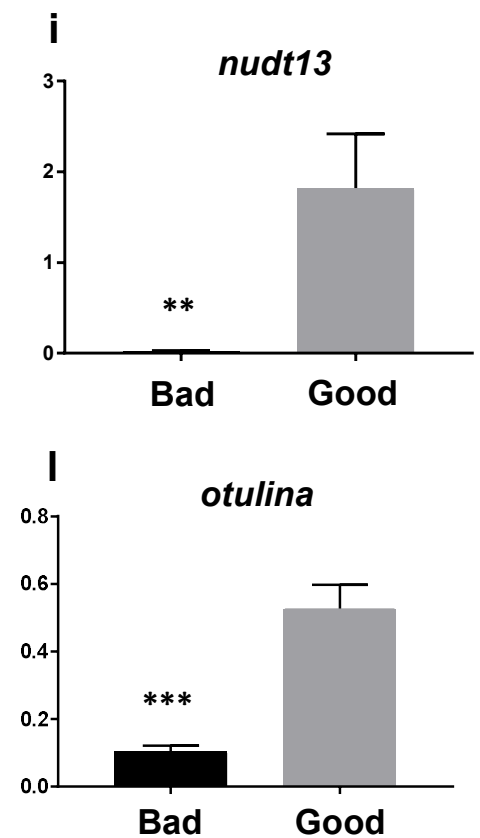

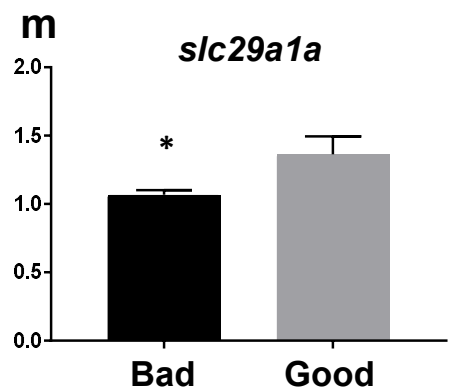




\section{Figure 5}

bioRxiv preprint doi: https://doi.org/10.1101/286815; this version posted March 23, 2018. The copyright holder for this preprint (which was not

.

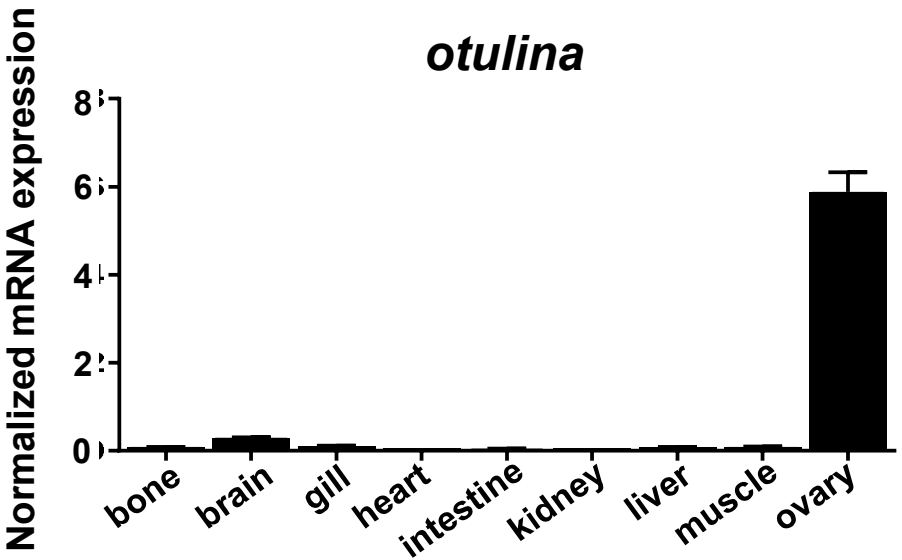

C

政 certified by peer review) is the author/funder. All righ hts reserved. No reuse allowed without permission.

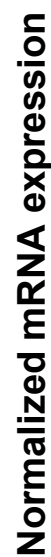

slc20a1a

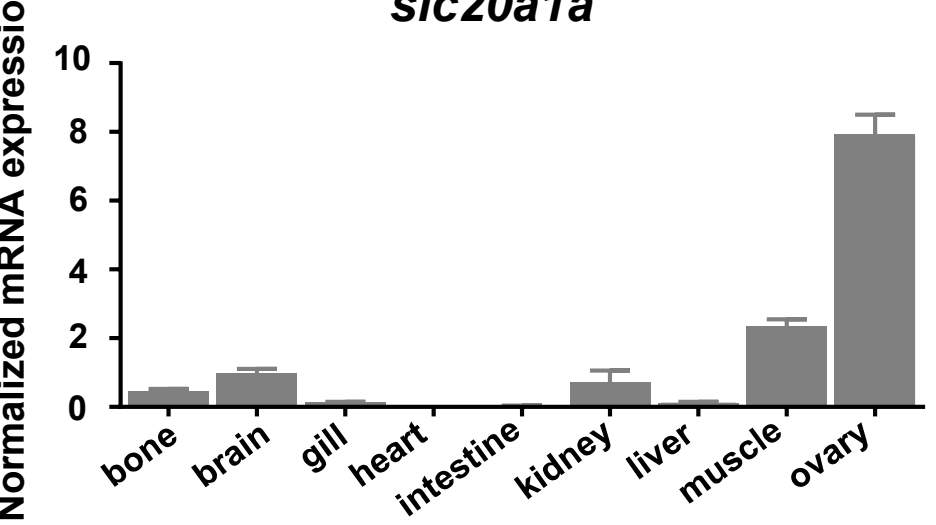

d

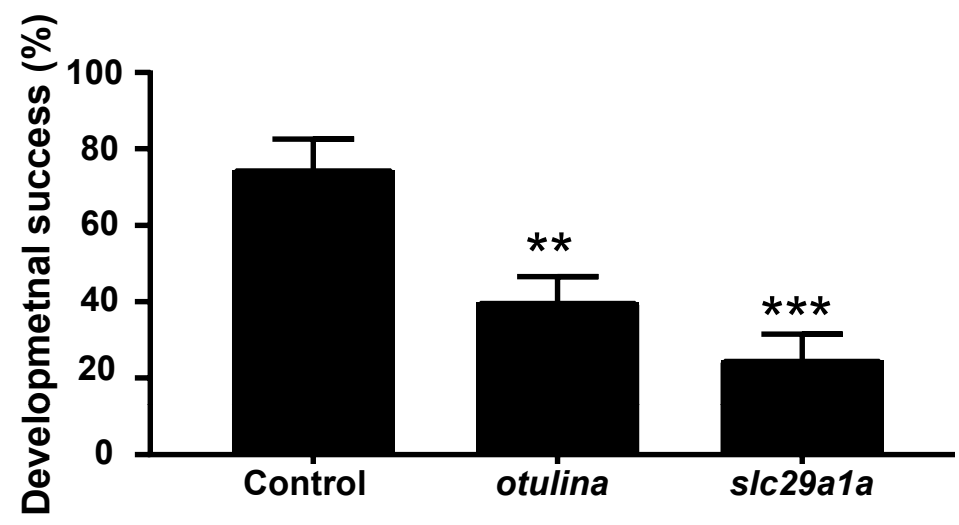




\section{Figure 6}

TimieRxiYpreprint doi: https://doi.org/10.1/01/286815; this version posted March 23, 2018. The copyright holder for this preprint (which was not 24
(hpf)
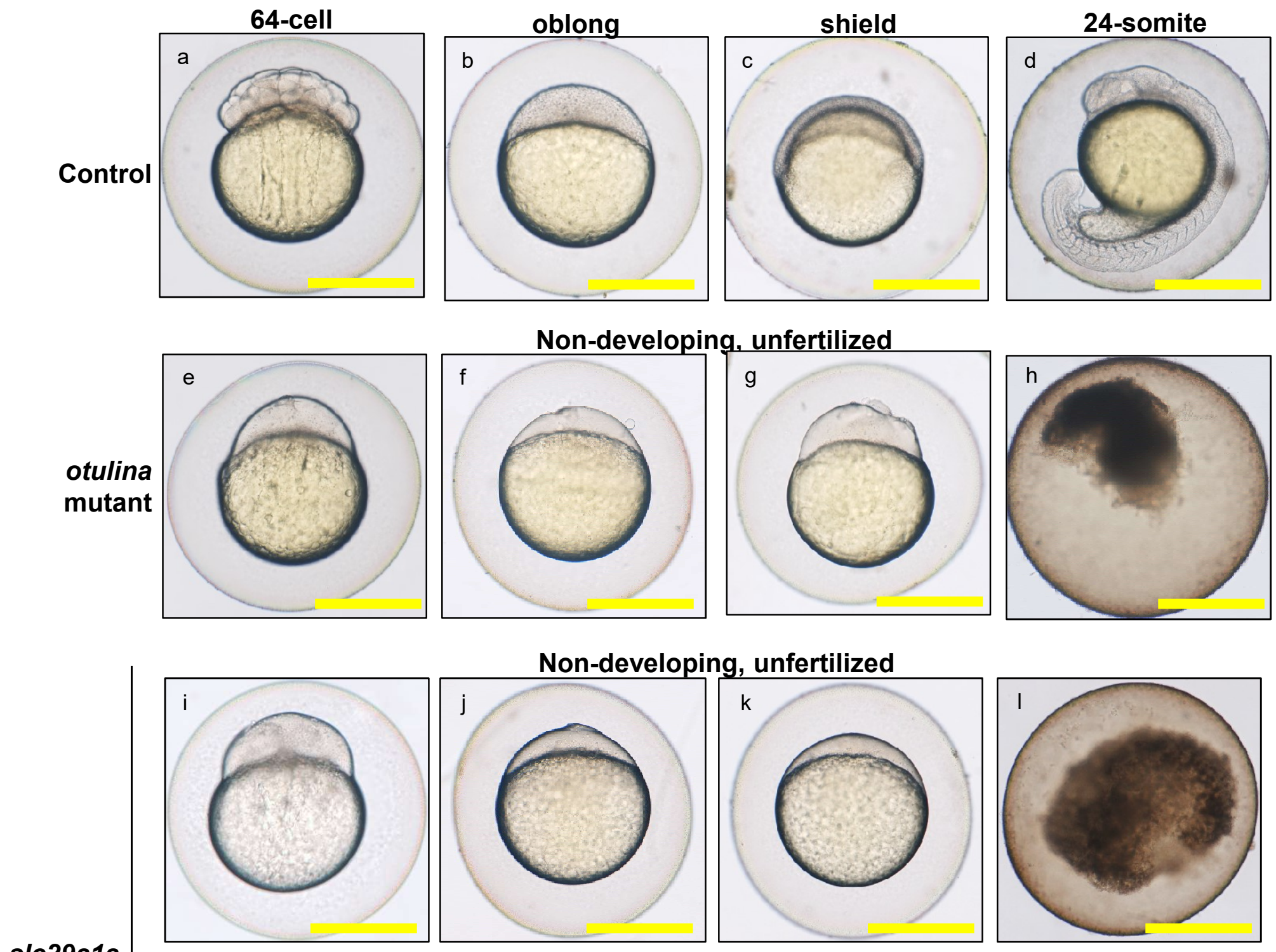

mutant

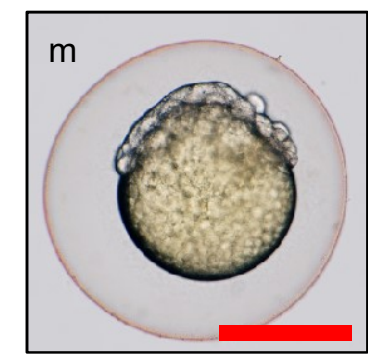

\section{Fertilized, developed abnormally until MBT}
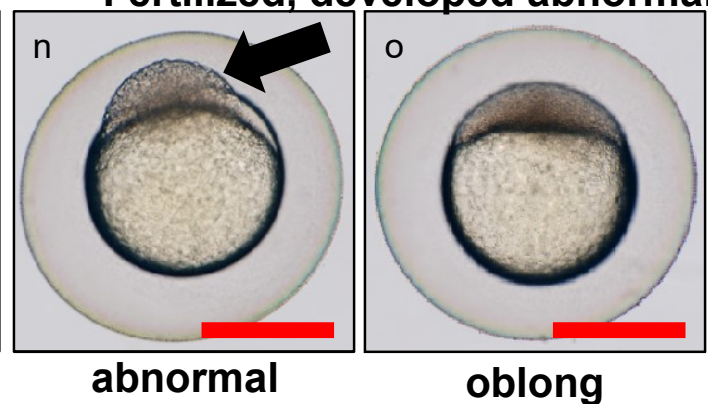
cell mound

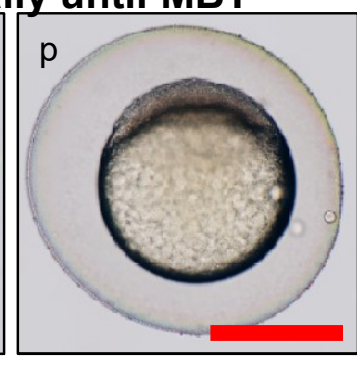

epiboly

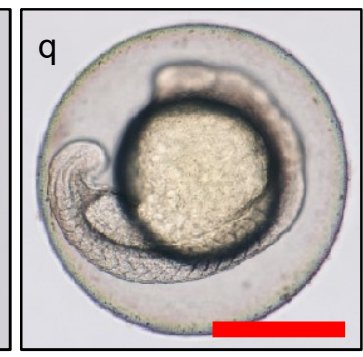

18-somite

$\mathbf{r}$
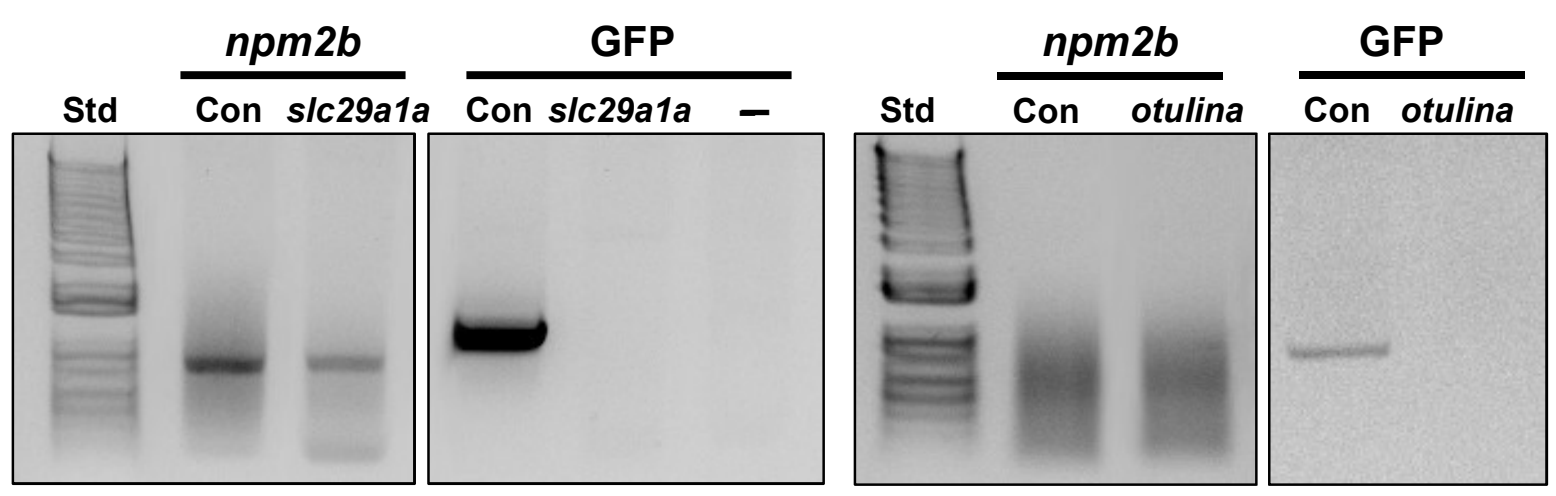


\section{Figure 7}

bioRxiv preprint doi: https://doi.org/10.1101/286815; this version posted March 23, 2018. The copyright holder for this preprint (which was not certified by peer review) is the author/funder. All rights reserved. No reuse allowed without permission.

a
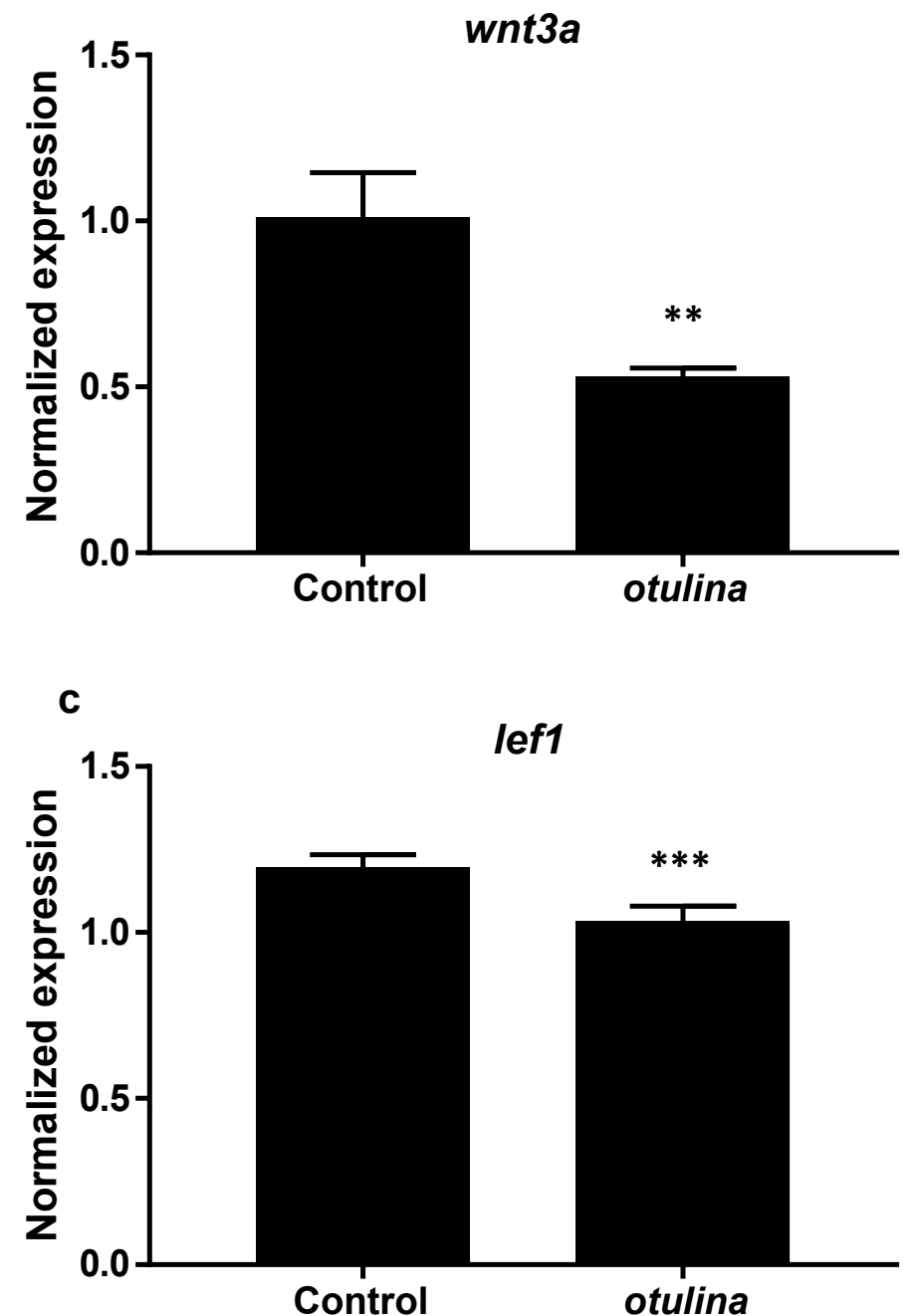

b
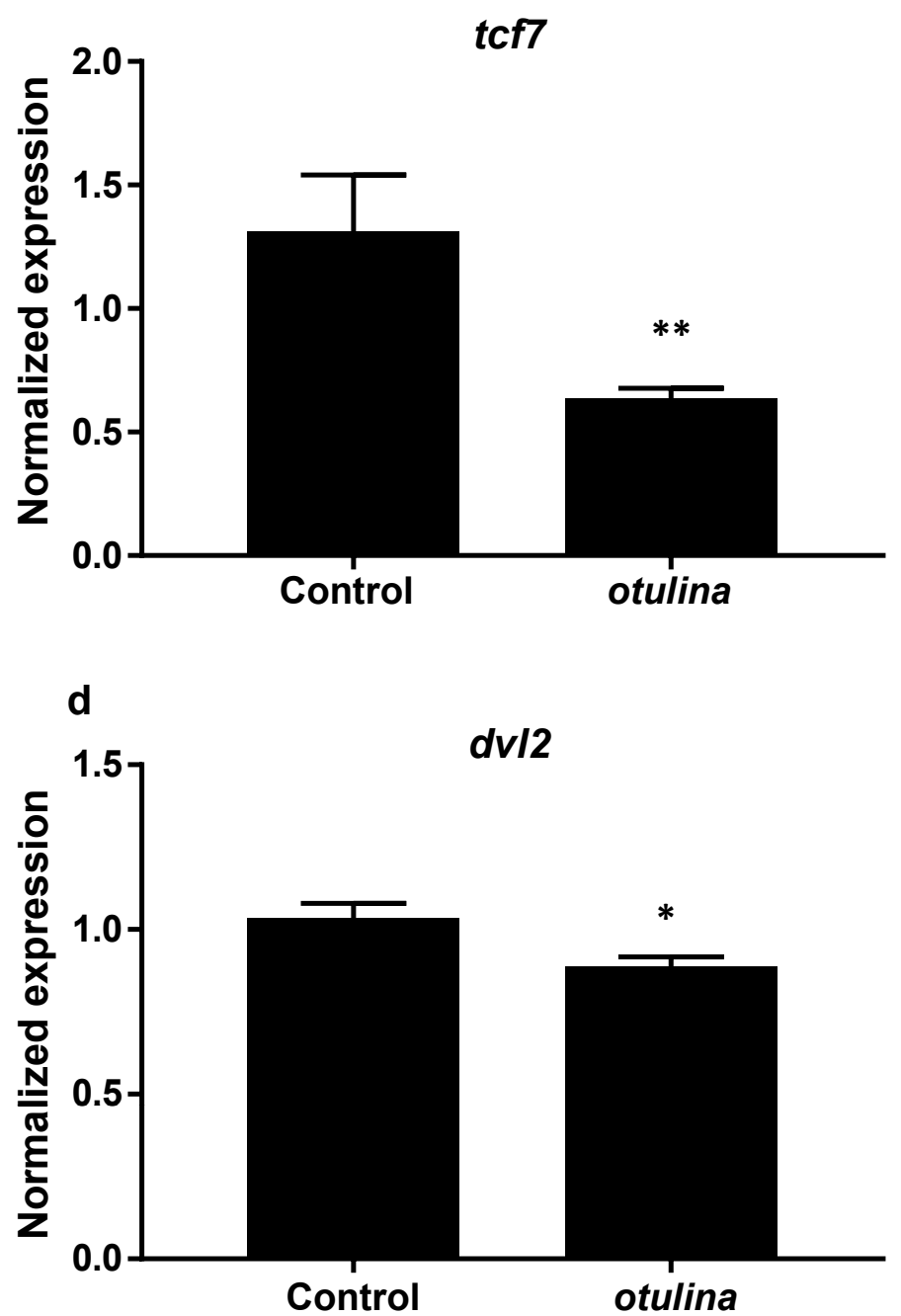


\section{Figure 8}

bioRxiv preprint doi: https://doi.org/10.1101/286815; this version posted March 23, 2018. The copyright holder for this preprint (which was not certified by peer review) is the author/funder. All rights reserved. No reuse allowed without permission.

a

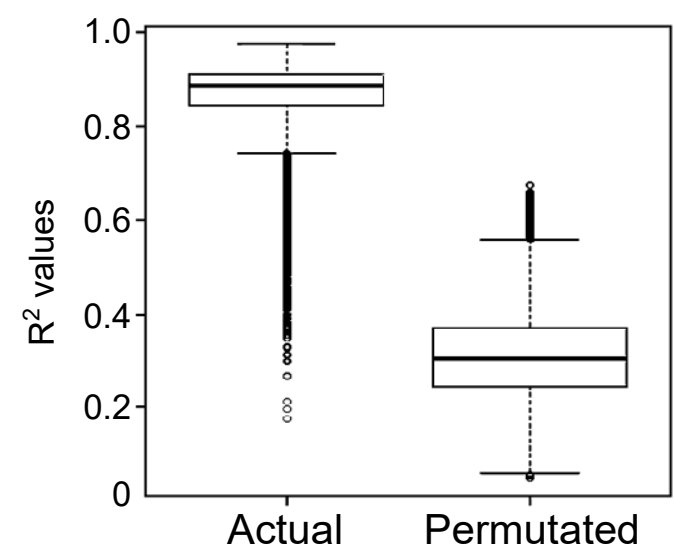

b

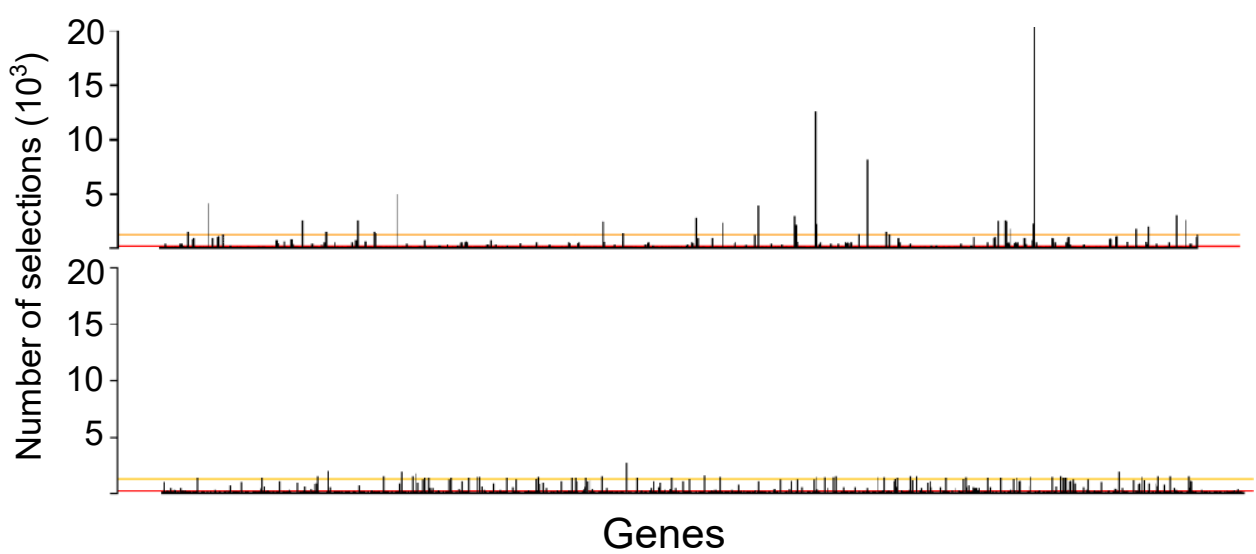

